15

\title{
Позиционно-чувствительные детекторы тепловых и холодных нейтронов с газовым конвертором ${ }_{2}^{3} \mathrm{He}$ (обзор)
}

\author{
() А.П. Кащук, О.В. Левицкая
}

Петербургский институт ядерной фризики им. Б.П. Константинова НИЦ КИ, 188300 Гатчина, Ленинградская обл., Россия

e-mail: anatoli.kachtchouk@cern.ch

Поступило в Редакцию 6 марта 2019 г.

В окончательной редакции 12 октября 2019 г.

Принято к публикации 24 октября 2019 г.

Представлен краткий аналитический обзор позиционно-чувствительных детекторов тепловых и холодных нейтронов, выполненных на газовом конверторе ${ }_{2}^{3} \mathrm{He}$. Основное внимание уделено новым подходам и техническим решениям, определяющим тенденции развития методики.

Ключевые слова: PSD, LPSD, MWPC, MSGC, MPGD, GEM, MHSP, MM.

DOI: $10.21883 /$ JTF.2020.04.49074.84-19

\section{Введение}

Тепловые и холодные нейтроны (ТХН) - электрически нейтральные частицы с длиной волны, сравнимой с размерами атомов и межатомными расстояниями, широко применяются для изучения структуры вещества. В отличие от рентгеновского и синхротронного излучений нейтроны взаимодействуют в основном с ядрами и магнитными моментами электронных оболочек атомов. Регистрация дифракционной картины составляет основу метода исследования структуры материалов: органических, биологических, металлов, полупроводников, керамик, изотопов с близкими атомными номерами и др. Обладая магнитным моментом, нейтроны испытывают магнитное рассеяние, что делает их уникальным инструментом для исследования магнитной структуры вещества. Поляризованные ТХН существенно расширяют возможности метода исследования магнитной структуры. Дифракция нейтронов позволяет исследовать динамику конденсированных сред, позволяет изучать материалы при воздействии на образец низких и высоких температур, давлений, электрических и магнитных полей, фазовые переходы и т.д. Исследования с применением ТХН являются уникальными и способными дать принципиально новую информацию для понимания функционирования живой клетки как целого. Выше представлен далеко не полный перечень областей применения ТХН, подробнее можно прочитать в работе [1].

Важным свойством ТХН является возможность их транспортировки в вакууме по нейтроноводам на большие расстояния так, что на одном источнике ТХН - исследовательском ядерном реакторе - можно разместить одновременно несколько нейтронных станций. Изогнутые на небольшой угол нейтроноводы одновременно с транспортировкой пучков нейтронов к образцам позволяют очистить их от гамма-фона, сопровождающего рождение нейтронов.
На высокопоточном реакторном комплексе ПИК (Гатчина) планируется создать до 50 исследовательских установок коллективного пользования для исследований в области ядерной физики и физики конденсированного состояния вещества [2].

Для измерения дифрактограмм регистрируется зависимость интенсивности рассеяния нейтронов от угла рассеяния, соответствующего условию Брэгга-Вульфа: $n \lambda=2 d \cdot \sin \theta$, где $n-$ порядок отражения $(n=1,2,3 \ldots), \lambda$ - длина волны нейтрона, $\theta-$ угол Брэгга, под которым наблюдается дифракция, $d$ межплоскостное расстояние кристаллической решетки исследуемого образца. Дифракционный луч распространяется под углом $2 \theta$ к первичному лучу. Точность измерения интенсивности дифракционных пиков и соответствующих им углов рассеяния - важнейшие характеристики дифрактометров.

Развитие экспериментальных методов нейтронной дифрактометрии тесно связано с достижениями техники позиционно-чувствительных детекторов ТХН - Position Sensitive Detector (PSD) ${ }^{1}$ [3]. Детекторные системы являются ключевыми элементами таких нейтронно-дифракционных установок как кольцевые дифрактометры, приборы малоуглового рассеяния, рефлектометры. Перечисленные экспериментальные установки работают в разных диапазонах углов $\theta$ и предназначены для решения разных задач. Большинство дифракционных приборов используют в качестве PSD пропорциональные счетчики и проволочные пропорциональные камеры MWPC Multi-Wire Proportional Chambers [3]. C 1988 г. для регистрации ТХН успешно применяются наполненные гелием микростриповые счетчики MSGC - Micro-Strip Gaseous Counters [4].

Последующий прогресс в развитии детекторов ионизирующих излучений не мог не коснуться детекторов ТХН. В последнее десятилетие (особенно, с созданием

\footnotetext{
1 Здесь и далее будут использоваться аббревиатуры, принятые в иностранной литературе, так как в отечественной литературе сокращения не устоялись.
} 


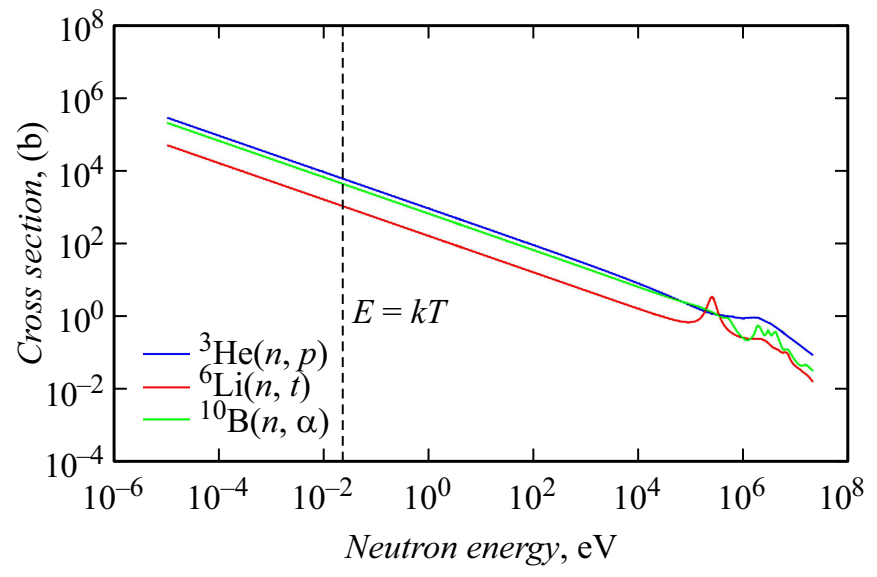

Рис. 1. Зависимости сечения захвата нейтрона ядрами изотопов ${ }_{2}^{3} \mathrm{He},{ }_{3}^{6} \mathrm{Li}$ и ${ }_{5}^{10} \mathrm{~B}$ от энергии нейтрона. Энергия $E=k T$ (штриховая линия) указывает на характерную границу раздела нейтронов по энергиям [5].

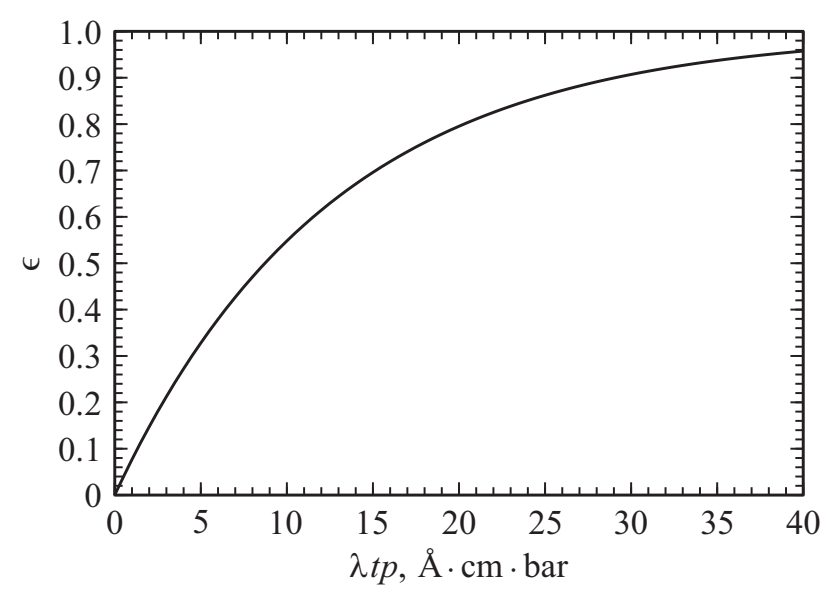

Рис. 2. Зависимость эффективности захвата нейтрона ядром ${ }^{3} \mathrm{He}$ от значения произведения $\lambda \cdot t \cdot p$.

Большого адронного коллайдера) в экспериментальной физике появился и бурно развивается новый

класс быстродействующих координатных детекторов, названных микроструктурными детекторами, MPGD Micro-Pattern Gaseous Detectors. Как будет показано ниже, эти детекторы уже начинают применяться для регистрации ТХН, на что, особенно, обращено внимание в настоящем обзоре. Это указывает на определенные перспективы: возможное увеличение быстродействия, улучшение пространственного разрешения и других важных характеристик детекторов для нейтронных дифрактометров.

Существует сравнительно небольшое количество конверторов $^{2}$ нейтронов в заряженные частицы, которые можно регистрировать. В основе конверсии лежит реакция нейтронного захвата, идущая с относительно большим сечением: $n+(A, z) \rightarrow(A+1, z)^{*}$, когда ядро

\footnotetext{
${ }^{2}$ Наряду с конвертором встречается термин радиатор.
}

атома-конвертора с зарядом $z$ и атомной массой $A$ соединяется с нейтроном $n$ и образует более тяжелое возбужденное ядро с атомной массой $A+1$ и зарядом $z$, распадающееся на заряженные фрагменты с выделением значительной энергии.

Самым лучшим среди газообразных конверторов является изотоп гелия ${ }^{3}-{ }_{2}^{3}$ Не. Для увеличения эффективности регистрации нейтронов необходима определенная концентрация ядер в чувствительной области детектора, поэтому повышается давление газа. Газовый конвертор ${ }^{3}$ Не используется с 80-х годов и до настоящего времени он является основным при детектировании $\mathrm{TXH}$, можно сказать, рабочей лошадкой с большим послужным списком [3]. Несмотря на существенное повышение стоимости изотопа ${ }^{3} \mathrm{He}$ в связи с кризисом, обусловленным резким снижением его производства 4 в США в 2000-е годы, в детекторах первых дифрактометров исследовательского реактора ПИК он будет основным конвертором [2]. В связи с подорожанием изотопа ${ }^{3} \mathrm{He}$ также и в России особенно актуальными становятся разработки с минимальным его расходом, а также создание детекторных систем с периодической регенерацией рабочей смеси.

Детектирование ТХН производится путем регистрации продуктов реакции радиационного захвата нейтрона ядром атома ${ }^{3} \mathrm{He}$ с распадом возбужденного нового ядра на две положительно заряженные частицы:

$$
n+{ }^{3} \mathrm{He} \rightarrow{ }^{3} \mathrm{H}+p+764 \mathrm{keV},
$$

где ${ }_{1}^{3} \mathrm{He}$ - тритон с энергией $191 \mathrm{keV}$ и $p-$ протон с энергией $573 \mathrm{keV}$ с суммарным энерговыделением $764 \mathrm{keV}$.

B настоящем обзоре нейтроны с энергией $E=$ $=E_{T}=k T=25.3 \mathrm{meV} \quad(k-$ постоянная Больцмана, $T=293 \mathrm{~K}-$ комнатная температура по Кельвину) будем считать тепловыми. Длина волны теплового нейтрона $\lambda_{0}=9.04 / \sqrt{ } E_{T}=1.8 \AA$, а сечение реакции (1) $\sigma\left(\lambda_{0}\right)=5333$ barn (рис. 1). Нейтроны с энергией $E<E_{T}$ до $E \sim 0.1 \mathrm{meV}$ считаются холодными, а с энергией $E>E_{T}$ до $E \sim 500 \mathrm{meV}$ - горячими, те и другие медленные нейтроны, например, скорость 5 теплового нейтрона $v_{0}=0.43 \sqrt{ } E_{T}=2.163 \mathrm{~km} / \mathrm{s}$. Указанный диапазон энергий и длин волн нейтронов наиболее часто используется в дифракционных экспериментах с нейтронами. В этом диапазоне сечение $\sigma(\lambda)=\sigma\left(\lambda_{0}\right) \cdot \lambda / \lambda_{0}$.

Если потерями нейтронов в материале входного окна пренебречь, то эффективность регистрации нейтрона можно оценить по эффективности захвата его

\footnotetext{
${ }^{3}$ Изотопная распространенность в природе: ${ }_{2}^{3} \mathrm{He}-0.00014 \%$, ${ }_{2}^{4} \mathrm{He}-99.99986 \%$, другие изотопы гелия нестабильны; заряд ядра $z=2$ далее в тексте будет опущен.

${ }^{4}$ https://www.researchgate.net/publication/285860794_The_Helium3_ Shortage_Supply_Demand_and_Options_for_Congress. В сообщении [6] отмечается, что в 1995 г. литр ${ }^{3}$ Не стоил $\sim 100$ US\$, а после 2014 г. $1500-4000$ US\$.

${ }^{5}$ На импульсных источниках измеряется время пролета нейтрона и с высокой точностью определяется длина волны и энергия нейтрона.
} 

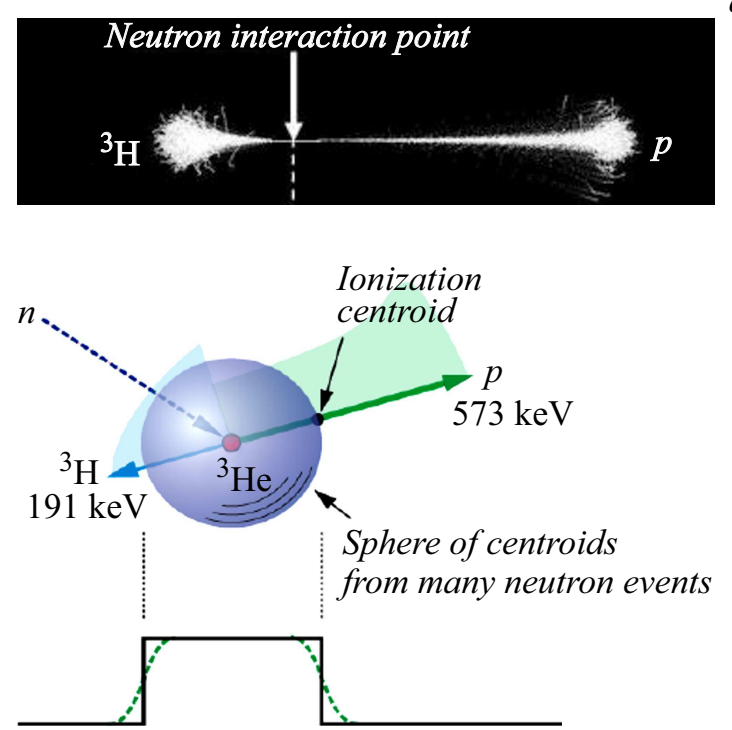

Distribution of centroids projected in one-dimension $a$

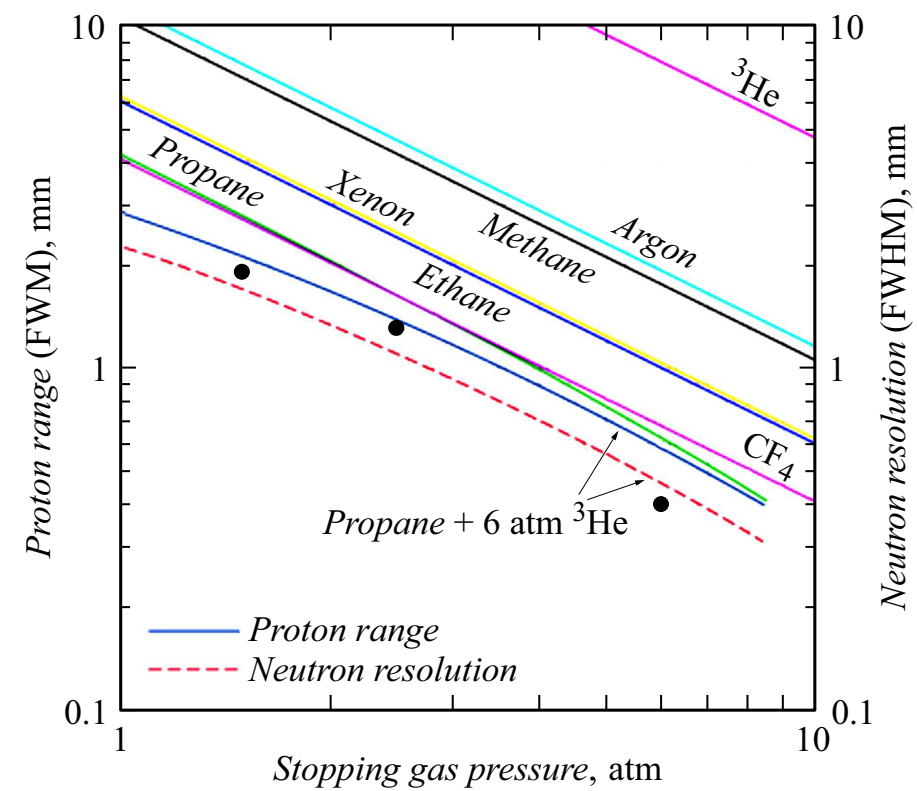

Рис. 3. $a$-центр тяжести первичного заряда систематически смещен в сторону пробега протона и лежит на сфере диаметром $\sim 0.8$ от длины пробега протона; $b-$ пробег протона и пространственное разрешение как функция давления различных добавок при давлении гелия 6 bar [5].

ядром ${ }^{3} \mathrm{He}$ :

$$
\varepsilon=1-\exp -\left\{\left[N_{1} \cdot \sigma\left(\lambda_{0}\right) / \lambda_{0}\right] \cdot \lambda \cdot t \cdot p\right\},
$$

где $N_{1}=N_{A} \cdot \rho / A$ - постоянная Лошмидта, $N_{A}-$ постоянная Авогадро, $A=3$ - атомная масса гелия, $\rho=A / 22.4 / 1000=0.000134\left[\mathrm{~g} / \mathrm{cm}^{3}\right]-$ плотность гелия при нормальных условиях, $N_{1} \cdot \sigma\left(\lambda_{0}\right) / \lambda_{0}=0.0796$, $\lambda_{0}=1.8 \AA, \lambda$ - длина волны нейтрона $[\AA], t-$ толщина слоя конвертора $[\mathrm{cm}], p$ - давление [bar].

Из графика, приведенного на рис. 2, видно, что эффективность детектора монотонно возрастает с увеличением длины волны нейтрона, толщины детектирующего слоя гелия и давления. Зная $\lambda$, для получения нужной эффективности необходимо выбрать соответствующие $t$ и $p$.

Продуктами реакции (1) являются две заряженные частицы, вылетающие из точки захвата нейтрона под углом $180^{\circ}$ друг к другу изотропно во всех направлениях, как показано на рис. 3 [5]. Такая кинематика обусловлена маленькой энергией захвата нейтрона и значительной энергией развала возбужденного ядра. Длины пробега фрагментов в газе не одинаковые. Это вносит погрешность в определение пространственных координат нейтрона.

Обычно регистрируется центр тяжести образованного в зазоре детектора заряда первичной ионизации или пропорционального ему заряда вторичной ионизации. Этот центр смещен в сторону пробега более энергичного протона и распределен в пространстве по сфере вокруг истинной точки (рис. 3,a). Диаметр сферы приблизительно составляет $0.8 L_{p}$, где $L_{p}$ - пробег протона [6] и определяет предельное пространственное разрешение ${ }^{6}$ детектора. При давлении гелия 1 bar пробег протона в гелии составляет $L_{p}=5.73 \mathrm{~cm}$. Для улучшения пространственного разрешения детектора необходимо уменьшать пробеги, поэтому увеличивают общее давление газовой смеси, добавляя к гелию многоатомный газ, например пропан $\left(\mathrm{C}_{3} \mathrm{H}_{8}\right)$. Могут быть применены и другие добавки: изобутан $\left(\mathrm{iC}_{4} \mathrm{H}_{10}\right)$, метан $\left(\mathrm{CH}_{4}\right)$, тетрафторметан $\left(\mathrm{CF}_{4}\right)$, тетрафторэтан $\left(\mathrm{C}_{2} \mathrm{~F}_{6}\right)$, углекислый газ $\left(\mathrm{CO}_{2}\right)$, благородные газы Хе, $\mathrm{Kr}, \mathrm{Ar}$, др. При парциальном давлении гелия $p=6 \operatorname{bar}(0.6 \mathrm{MPa})$ с толщиной конверторного слоя $t=1.5 \mathrm{~cm}$ получим эффективность захвата нейтрона с длиной волны $\lambda_{0}=1.8 \AA$, приблизительно равную $70 \%$, а чтобы получить пространственное разрешение $1 \mathrm{~mm}$, необходимо добавить пропана с давлением 3 bar (рис. 3,b). Следует иметь в виду, что пропан при давлении 8.5 bar образует конденсат. Многоатомные добавки образуют радикалы в рабочей смеси в условиях воздействия радиации и электрического поля, отравляющие газ при длительной работе детектора, что является их недостатком. Добавка $\mathrm{CF}_{4}$ приводит к увеличению скорости дрейфа электронов, что важно для улучшения временно́го разрешения детектора, но приводит к существенной потере первичных электронов за счет прилипания электронов с образованием отрицательных ионов. Для получения пространственного разрешения $\sim 1 \mathrm{~mm}$ в чистом гелии ${ }^{3} \mathrm{He}$ требуется давление не менее 30 bar при $t=1.5 \mathrm{~cm}$.

\footnotetext{
${ }^{6}$ Пространственное разрешение здесь и далее приводится как Full Width Half Maximum (FWHM) - полная ширина на полувысоте.
} 

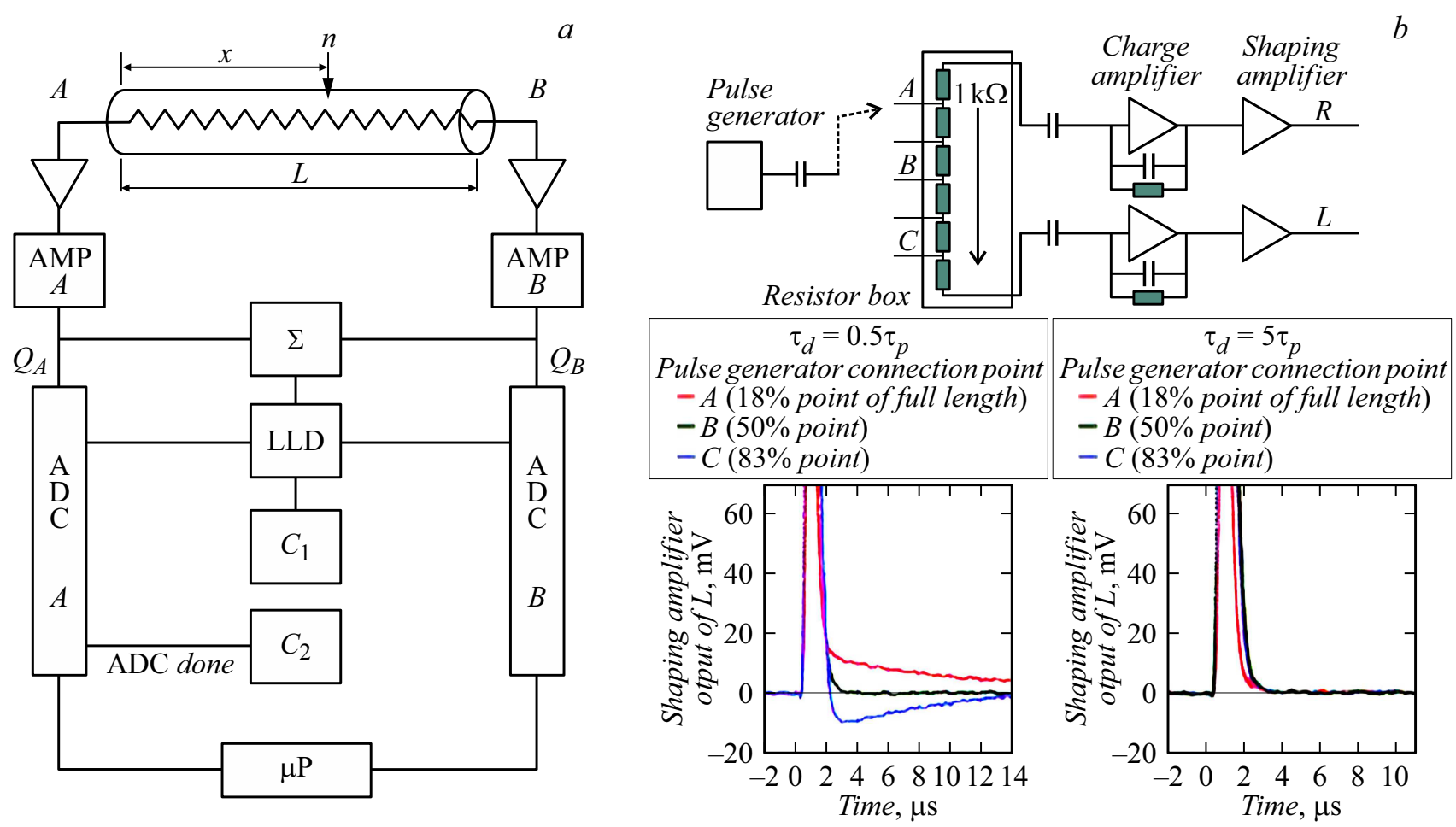

Рис. 4. Основные узлы электроники LPSD: $a$ - зарядо-чувствительный предусилитель (интегратор), усилитель-формирователь с компенсацией хвоста и восстановителем базовой линии, аналого-цифровой преобразователь (ADC), процессор [8]; $b-$ иллюстрация к компенсации ионного хвоста [9].

\section{Однокоординатные детекторы на газоразрядных пропорциональных счетчиках-трубках}

Цилиндрический пропорциональный счетчик (LPSD - Linear Position Sensitive Detector, линейный позиционно-чувствительный детектор) как детектор ионизирующего излучения применяется более 70 лет [3]. Трубки, наполненные изотопом гелия 3 Не с определенным давлением ${ }^{7}$, можно купить, см. [7]. Коммерчески доступные трубки имеют минимальный диаметр $6.3 \mathrm{~mm}$ (1/4 inch), типовой $-12.7 \mathrm{~mm}$, а длину — до $3 \mathrm{~m}$.

Координата нейтрона в LPSD определяется вдоль проволочки по сигналам с концов трубки $[8,9]$ делением заряда (рис. 4). Отсюда название - LPSD. Особенностью трубки и ее большим достоинством является то, что она хорошо держит давление $10-30 \mathrm{bar}$, оставаясь относительно тонкостенной $\sim 1 \mathrm{~mm}$ (и меньше для трубки из нержавеющей стали) независимо от длины трубки. Суммарный сигнал с концов трубки обычно подается на дискриминатор для режекции гамма-фона по амплитуде импульса. Пространственное разрешение поперек трубки равно диаметру трубки, так как неизвестно, в какой точке в газе происходит захват нейтрона. Для

\footnotetext{
${ }^{7}$ Коэффициент газового усиления и скорость дрейфа электронов зависят от $E / p$ ( $E$ - напряженность поля, $p$ - давление газа). С ростом давления в газоразрядных детекторах необходимо увеличивать напряжение для сохранения неизменным отношения $E / p$.
}

устранения этого недостатка нейтроны направляются на трубки щелевыми коллиматорами (например, см. [10]). На рис. 4 приведены основные узлы электроники детектора. На разрешение вдоль трубки оказывает влияние не только смещение центра тяжести заряда относительно истинного положения точки захвата нейтрона ядром гелия, но и шум усилителя ENC - Equivalent Noise Charge [11]. Эта характеристика электроники имеет минимум, соответствующий оптимальному времени интегрирования (формирования) сигнала $T_{o p}=C_{D} \sqrt{ }\left(R_{s} R_{p}\right)$, где $C_{D}$ - емкость детектора (трубки) на входе усилителя, а $R_{s}$ и $R_{p}$ - шумовые резисторы, подключенные соответственно последовательно и параллельно входу усилителя. В последовательной компоненте доминируют емкость $C_{D}$ и сопротивление анодной проволочки $\left(R_{s}=3-10 \mathrm{k} \Omega\right.$ для проволочки из никеля диаметром $15-20 \mu \mathrm{m})$, а в параллельной компоненте - резистор, через который подается рабочее напряжение на проволочку $\left(R_{p} \approx 1 \mathrm{M} \Omega\right)$. Условие минимума соответствует равенству последовательной и параллельной компонент шума.

Благодаря уменьшению времени формирования сигнала до $0.1 \mu \mathrm{s}$ в работе [9], где использовались трубки диаметром $12.7 \mathrm{~mm}$ длиной $600 \mathrm{~mm}$, скорость счета удалось увеличить до $10^{5} \mathrm{~s}^{-1}$ /wire (count per $1 \mathrm{~s}$ per 1 wire), при этом получено разрешение вдоль трубки $3.5 \mathrm{~mm}$ - меньше 1\% от длины трубки. Мультидетек- 
тор из десяти трубок, работающих независимо, может обеспечить скорость счета $10^{6} \mathrm{~s}^{-1}$.

Для получения высокой скорости счета обязательным элементом в цепи усилителя является восстановитель базовой линии (Baseline Restorer). Он препятствует сдвигу базовой линии из-за наложения импульсов при статистических колебаниях загрузки. Этот сдвиг уровня вызывает разделительный конденсатор, через который анодная проволочка подключается к предусилителю, дифференцирующий сигнал. Для минимизации мертвого времени в канале регистрации должен быть также скомпенсирован относительно длинный хвост в сигнале, который наводится движущимися от анода к катоду положительными ионами. Методика оптимального формирования сигналов, подлежащих регистрации, а также компенсации ионного хвоста, хорошо представлена в работе [12].

В совместной работе $\operatorname{ILL}^{8}$ и $\operatorname{LLB}^{9}$ [13], опубликованной в 2016 г., описан двухкоординатный кольцевой дифрактометр, выполненный по типу банана на трубках с расстоянием до образца $1.5 \mathrm{~m}$ и покрывающий интервал углов $2 \theta=132^{\circ}$ с шагом $0.2^{\circ}$. Это - пример мультидетектора на 256 трубках с диаметром $12.7 \mathrm{~mm}$ и длиной $500 \mathrm{~mm}$. Трубки наполнены чистым гелием ${ }^{3} \mathrm{He}$ под давлением 30 bar. Такое техническое решение позволило в 22 раза расширить диапазон переданных импульсов $Q=(4 \pi / \lambda) \sin \theta=2 \pi / d$, соответственно уменьшив важный параметр $d=2 \pi / Q$. При этом диапазон по $\lambda$ составляет 0.57-1.1 $\AA$, а эффективность регистрации нейтронов с $\lambda=0.72 \AA-80 \%$. Достигнутое при этом быстродействие позволило регистрировать дифрактограммы in situ (за одну вспышку) при потоке нейтронов на образце до $10^{7} \mathrm{n} \cdot \mathrm{s}^{-1} \cdot \mathrm{cm}^{-2}$.

Необходимо подчеркнуть, что важным преимуществом детекторов ТХН, выполненных на трубках, является высокая ремонтопригодность (трубку легко заменить). К недостаткам следует отнести: низкое быстродействие; неоднородность эффективности регистрации нейтронов поперек трубки; наличие зазоров между трубками, из-за чего уменьшается светосила; наличие ошибки параллакса в измеряемой координате при отклонении пучка нейтронов от горизонтальной плоскости дифрактометра, что проявляется в размытии дифракционных линий спектра.

\section{Однокоординатные и двухкоординатные детекторы на проволочных пропорциональных камерах - MWPC}

MWPC, как и трубка, работает в пропорциональном режиме. Но камера отличается от трубки существенно лучшим пространственным разрешением поперек анодных проволочек, которое определяется их шагом. Типовой шаг анодных проволочек в MWPC 2-3 mm, шаг

\footnotetext{
${ }^{8}$ ILL - Institute Laue Langevin, Grenoble.

${ }^{9}$ LLB - Laboratoire Leon Brillouin, Saclay.
}

катодных проволочек 1-2 mm. Последние могут быть ориентированы как параллельно, так и перпендикулярно анодным проволочкам.

Первые детекторы для нейтронных дифрактометров, выполненные на MWPC с конвертором ${ }^{3} \mathrm{He}$, появились в 70-х г. следом за изобретением MWPC. Выделяются две школы, где были созданы самые большие, с наилучшим разрешением, и самые быстродействующие детекторы: BNL ${ }^{10}$ и ILL. По мнению авторов обзора, наибольшее число интересных методических работ в этой области опубликовано сотрудниками этих центров. В работах $[14,15]$ из BNL позиционно-чувствительный детектор на MWPC имеет рабочий зазор $t=1.5 \mathrm{~cm}$, расположенный сразу же за входным окном детектора. Металлический корпус является электростатическим экраном, в котором установлено три электрода: первый - проволочный катод, за ним - проволочный анод и второй катод, последний - не обязательно проволочный $^{11}$. Как видно из рис. 5, это - симметричная проволочная камера с равными расстояниями анод-катод, размещенная на выходном окне герметичного корпуса. В рабочем зазоре детектора вдоль траектории разлетающихся заряженных фрагментов реакции (1) образуется приблизительно 25 тысяч первичных пар электрон-ион, $\sim 4 f C$ - довольно большой заряд. Первичные электроны дрейфуют по линиям электрического поля к анодным проволочкам. У самой поверхности анодной проволочки в сильном электрическом поле происходит лавинное умножение электронов с образованием вторичных электрон-ионных пар. Коэффициент газового усиления определяется отношением вторичного заряда к первичному. Заряд положительных ионов, удаляющийся от анодной проволочки к катоду, индуцирует импульсы на окружающих анодную проволочку электродах: на ближайшей анодной проволочке наводится импульс отрицательной полярности, на катодных проволочках импульсы положительной полярности. Подчеркнем, что вторичные электроны проходят очень короткий путь до проволочки $\sim 100 \mu$, практически не наводя сигнала, основной сигнал - от ионов. Амплитуда и длительность наведенных импульсов сильно флуктуируют в зависимости от ориентации первичных треков. Для полного собирания заряда необходимо увеличивать время интегрирования, а это уменьшает быстродействие. В рассматриваемых работах шаг анодных и катодных проволочек $1.6 \mathrm{~mm}$. При оптимальном формировании $0.25 \mu \mathrm{s} \mathrm{ENC}=256 \mathrm{e}+6.73 \mathrm{e} / \mathrm{pF}$, что позволило получить разрешение $1.5 \mathrm{~mm}$. Катодные проволочки, при помощи которых здесь измеряется координата $(X)$ поперек анодных проволочек, ориентированы параллельно анодным проволочкам и объединены в стрипы по 6 штук. Стрипы подключены к резистивному делителю, как показано на рис. 5. К резистивному делителю подключены и

\footnotetext{
${ }^{10}$ BNL - Brookhaven National Laboratory, New-York.

${ }^{11}$ На пути нейтронов до их регистрации не должно быть органических материалов, содержащих водород, который сильно рассеивает нейтроны.
} 


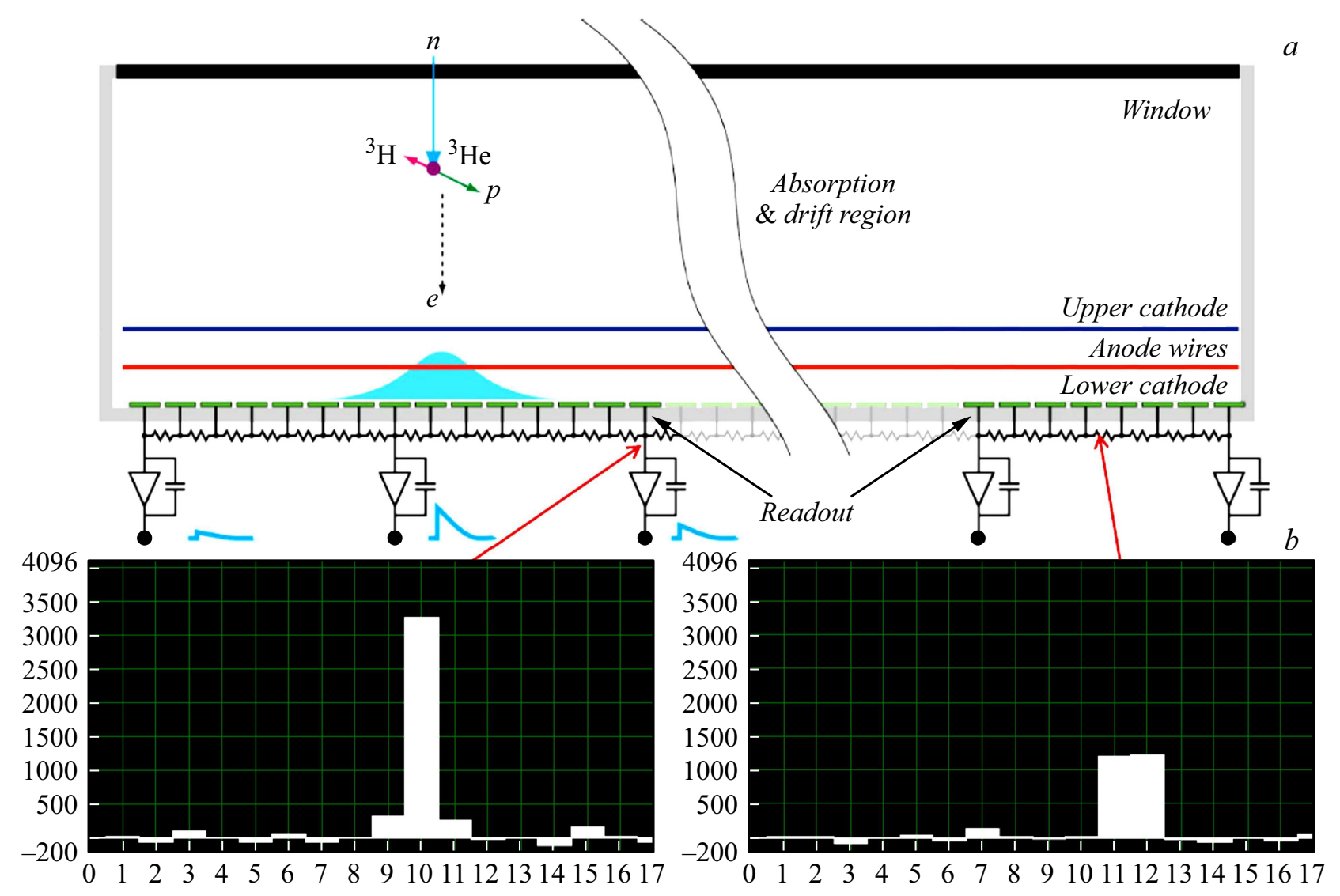

Рис. 5. $a-$ схема позиционно-чувствительного детектора на проволочной пропорциональной камере (MWPC); $b-$ определение координаты по центру тяжести амплитуд импульсов на смежных катодных стрипах [14].

усилители с шагом $1 \mathrm{~cm}$. В приведенной конструкции благодаря резистивному делителю уменьшена емкость детектора $C_{D}$, включенная параллельно входу усилителя, что позволило уменьшить шумы. Метод позволяет получить при шаге стрипов $1 \mathrm{~cm}$ миллиметровое разрешение. Координата определяется цифровым сигнальным процессором, как

$$
X=N \cdot D+\left[\left(Q_{N+1}-Q_{N}\right) /\left(Q_{N-1}+Q_{N}+Q_{N+1}\right)\right] \cdot D,
$$

где $N=1,2,3 \ldots N_{\max }$ - номер стрипа, $Q_{N}$ - измеренный заряд на стрипе $N, D$ - шаг стрипов, (рис. 6).

Детектор применен в кольцевом дифрактометре с апертурой $120^{\circ} \times 15^{\circ}$ [16]. Он содержит 8 модулей MWPC, размещенных в общем газовом объеме с гелийпропановой смесью 7/2.5 bar. Чувствительная область всех модулей детектора $3000 \mathrm{~cm}^{2}-1.5 \mathrm{~m}$ по горизонтали и $20 \mathrm{~cm}$ по вертикали (рис. 7). Эффективность регистрации нейтронов для длин волн $\lambda=1-10 \AA$ превышает $50 \%$ с толщиной конверторного слоя $t=1.5 \mathrm{~cm}$ при указанном давлении. Параллакс при измерении $X$-координаты исключен изгибом детектирующей поверхности каждого модуля (рис. 8). На определение координаты в отдельном модуле затрачивалось $4 \mu \mathrm{s}$. Восемь модулей работали как независимые счетчики, что обеспечивало счет $2 \cdot 10^{6} \mathrm{~s}^{-1}$.

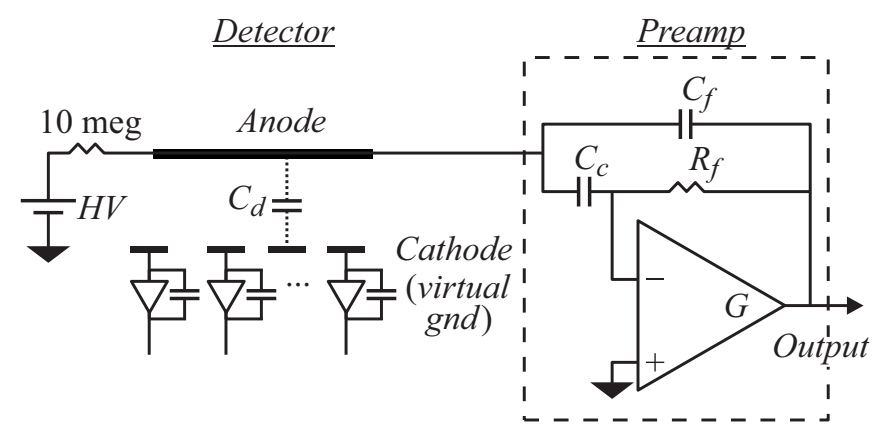

Рис. 6. Схема электроники регистрации координаты по центру тяжести амплитуд импульсов на катодных стрипах MWPC [14].

В детекторе для дифрактометра малоуглового рассеяния нейтронов необходима вторая координата $(Y)$. Последняя определяется так же, как первая $(X)$ при помощи катодных проволочек, но ориентированных перпендикулярно анодным проволочкам. Оптимальным выбором времени формирования получено пространственное разрешение $1.5 \mathrm{~mm}$ по обеим координатам. На рис. 9 показано, что на пространственное разрешение поперек проволочек влияет шаг намотки проволочек [14]. В этой работе показано, как можно уменьшить модуляцию в 


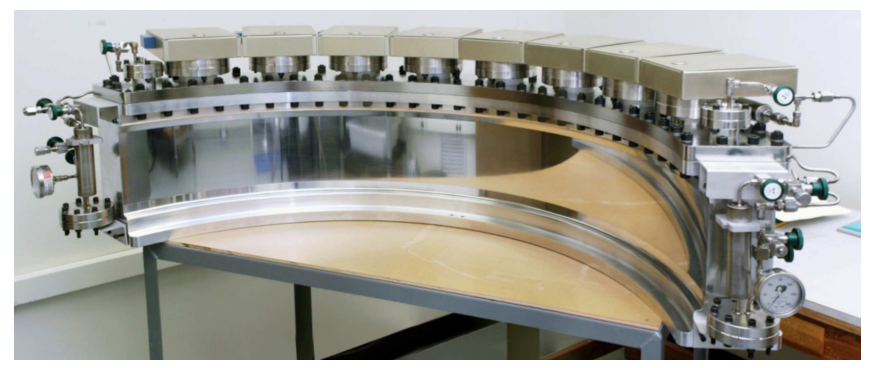

Рис. 7. Детектор ТХН для кольцевого дифрактометра с апертурой $120^{\circ} \times 15^{\circ}$ с расстоянием до образца $70 \mathrm{~cm}$, выполненный из восьми модулей MWPC с изгибом детектирующей поверхности для устранения параллакса [15].

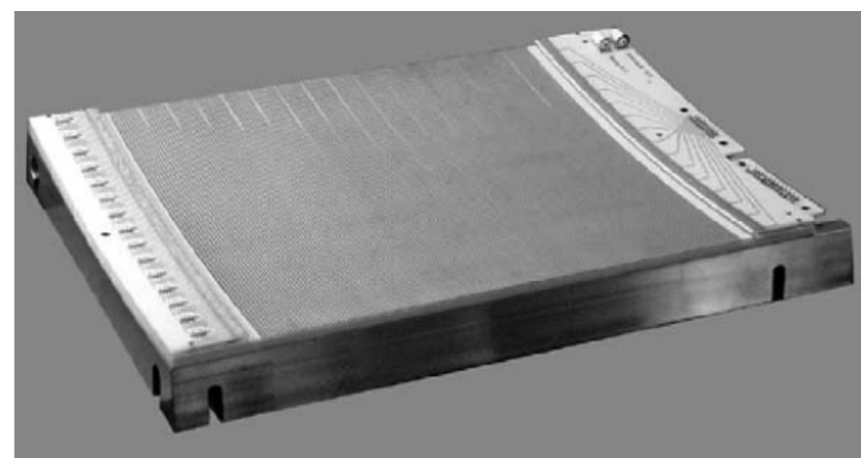

Рис. 8. Модуль MWPC с цилиндрической детектирующей поверхностью с радиусом $70 \mathrm{~cm}$ [14].

2 раза специальным электрическим полем, созданным в рабочем зазоре.

Отметим, что приведенные результаты [14-16] получены при относительно небольшом заряде $0.1-0.2 \mathrm{pC}$ (60-120 тысяч электронов) при газовом усилении MWPC $\sim 20$. При бо́льшем времени интегрирования можно уменьшить газовое усиление, т.е. при разработке детектора требуется определенная оптимизация. Подчеркнем также чем меньше газовое усиление, тем меньше флуктуации, связанные с усилением, тем лучше энергетическое разрешение и выше уровень отделения сигнала от гамма-фона. Нужно иметь в виду, что в MWPC, как и в пропорциональной трубке, при коротком времени формирования порядка $0.1 \mu$ s регистрируется не весь заряд, а $10-20 \%$, что обусловлено баллистическим дефицитом. Дефицит возникает из-за малого времени интегрирования сигнала относительно полного времени дрейфа положительных ионов, которое составляет десятки микросекунд.

B BNL было выпущено несколько детекторов, предназначенных для кольцевых порошковых дифрактометров, выполненных по приведенной выше довольно удачной разработке. Для приборов малоуглового рассеяния нейтронов была также выпущена серия двухкоординатных камер $200 \times 200 \mathrm{~mm}$, где обе координаты определялись делением заряда: $X-$ с первого, а $Y-$ со второго катода. В середине 80-х годов был сделан детектор ТХН c апертурой $500 \times 500 \mathrm{~mm} \mathrm{c}$ рекордной стабильностью измерения координат $X$ и $Y(\sigma=50 \mu)$, а на маленькой камере $50 \times 50 \mathrm{~mm}$ было получено рекордное для нейтронов и MWPC субмиллиметровое разрешение $400 \mu$ (FWHM). Следует отметить, что такое пространственное разрешение получено с шагом проволочек $1 \mathrm{~mm}$, а в MWPC больших размеров такой шаг выполнить трудно.

В работе [17] описан двухкоординатный позиционночувствительный детектор на MWPC с размерами активной площади $500 \times 500 \mathrm{~mm}$, созданный еще в 1986 г. и предназначенный для исследования протеинов методом малоуглового рассеяния нейтронов. Характеристики этого детектора считаются вполне востребованными до настоящего времени: эффективность регистрации холодных нейтронов с $\lambda=5 \AA$ не хуже $75 \%$, пространственное разрешение $2 \mathrm{~mm}$. Общее давление гелий-пропановой смеси 5.7/1.6 bar позволило ограничить пробег энергичного протона до $2.3 \mathrm{~mm}$. К недостатку можно отнести низкое быстродействие $-10^{5} \mathrm{~s}^{-1}$.

Интересной представляется японская разработка двухкоординатного детектора TXН на MWPC с цифровой регистрацией сигналов с каждой проволочки первого катода и с каждого печатного стрипа второго катода [18] (рис. 10). Шаг анодных и катодных проволочек $1 \mathrm{~mm}$. Расстояния от анодных проволочек до катодных $1 \mathrm{~mm}$ - равно шагу, а до катодных стрипов $1.5 \mathrm{~mm}$ (камера несимметричная). Координаты нейтрона определяются по центру группы (кластера) сработавших каналов, который вычисляется по формуле

$$
L(x, y)=\left[(x h-x l)^{2}+(y h-y l)^{2}\right]^{1 / 2},
$$

а ошибка с учетом предполагаемой длины пробега протона $L_{p}$ и тритона $L_{t}-$ по формуле

$$
P_{\mathrm{err}}(x, y)=L(x, y) \cdot L_{p} /\left(L_{p}+L_{t}\right) L(x, y) / 2,
$$

где индексами $h$ (high) и $l$ (low) обозначены крайние сработавшие каналы. В работе отмечается, что на

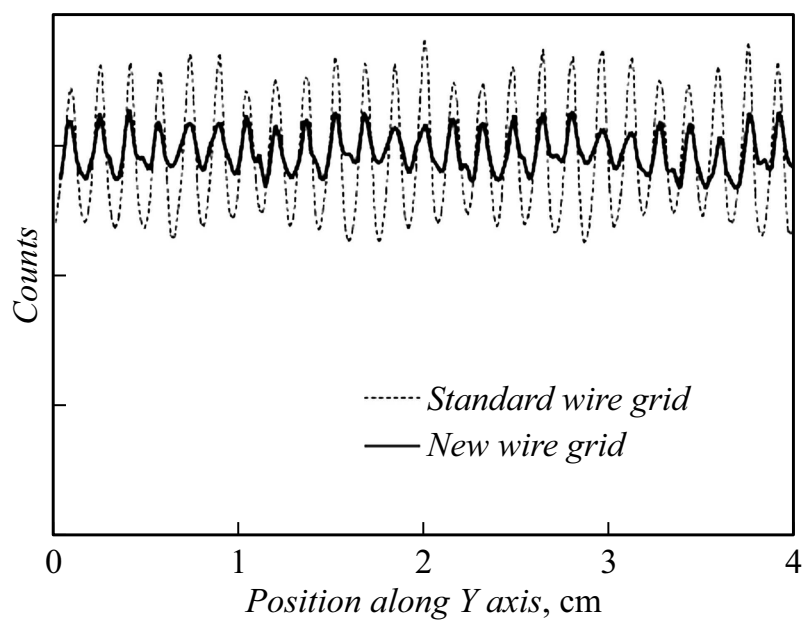

Рис. 9. Пространственное разрешение MWPC поперек проволочек в двух конструкциях камеры; видна модуляция с частотой шага анодных проволочек [14]. 
бинарной газовой смеси ${ }^{3} \mathrm{He} / \mathrm{CF}_{4}(20 \%)$, заполняющей конверсионный зазор $t=2 \mathrm{~cm}$ при суммарном давлении 6 bar $(0.6 \mathrm{MPa})$, получена для тепловых нейтронов эффективность 74\%, а пространственное разрешение $\mathrm{FWHM}=1.55 \mathrm{~mm} \quad(\sigma=0.66 \mathrm{~mm})$ с высокой однородностью по площади детектора. При этом чувствительность к гамма-фону от источника ${ }^{60}$ Со составила $8.2 \times 10^{-9}$. Добавка к гелию $\mathrm{CF}_{4}$ используется для увеличения скорости дрейфа электронов и уменьшения диффузии.

В ряде задач съем координатной информации с MWPC производится в полярных координатах, более естественных для регистрации дифракционной картины, как это представлено в работе [19] (рис. 11). Недостатком конструкции является наличие на пути нейтронов органического вещества в виде печатной платы первого катода, в составе которой в эпоксидном клее содержится водород, рассеивающий нейтроны.

В работе [20] приведена многопроволочная структура, выполненная по типу дрейфовых камер, где в газе размещены 1024 дрейфовые ячейки анод-катод в
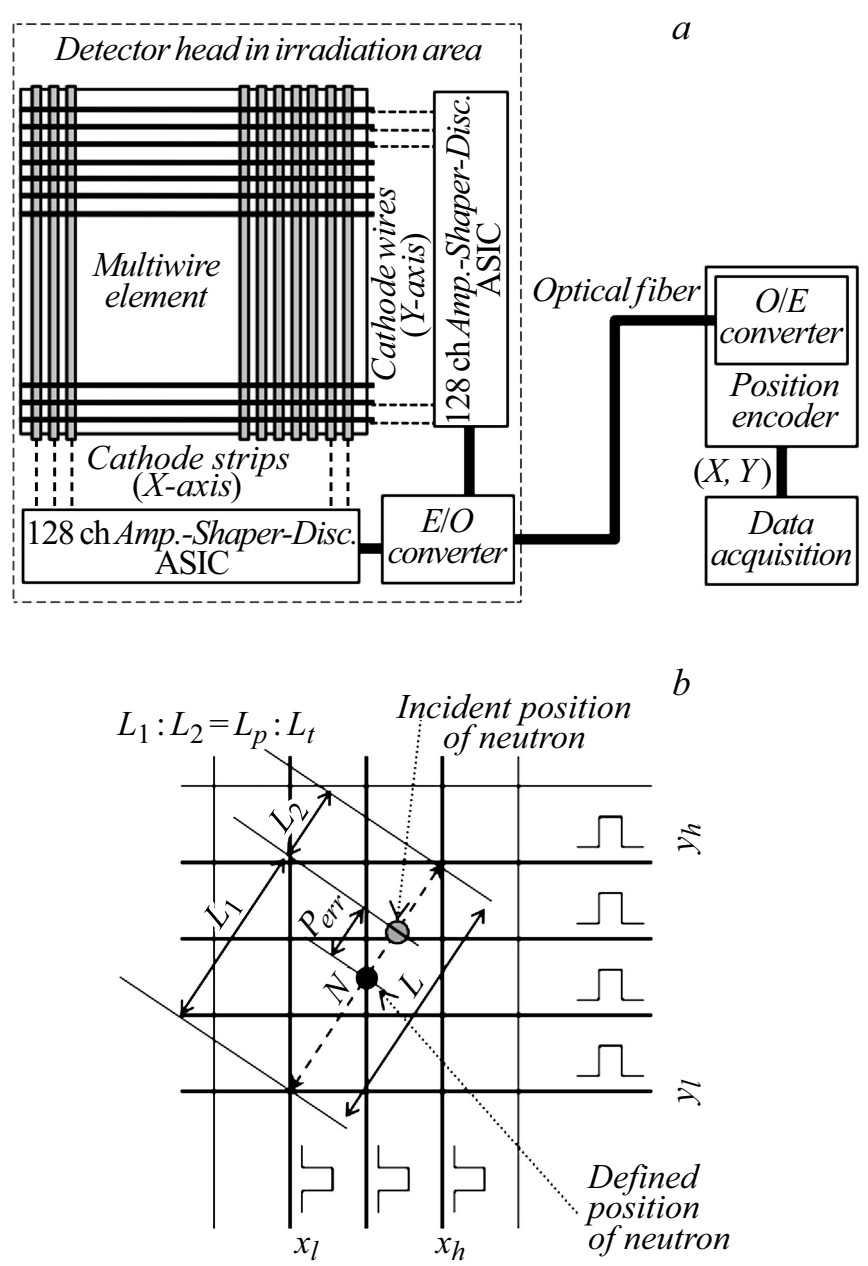

Рис. 10. $a$-двухкоординатный детектор ТХН на MWPC со считыванием сигналов с каждой катодной проволочки и каждого стрипа; $b-$ иллюстрация к определению координат с учетом длины треков протона и тритона [18].

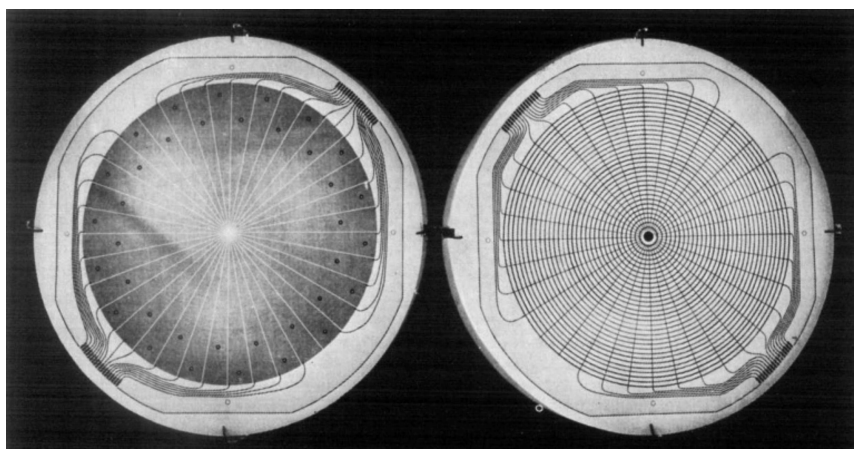

Рис. 11. Полярные координаты, созданные на двух печатных катодах MWPC в виде 29 концентрических окружностей с шагом $1 \mathrm{~cm}$ и 36 угловых секторов с шагом $10^{\circ}$ [19].

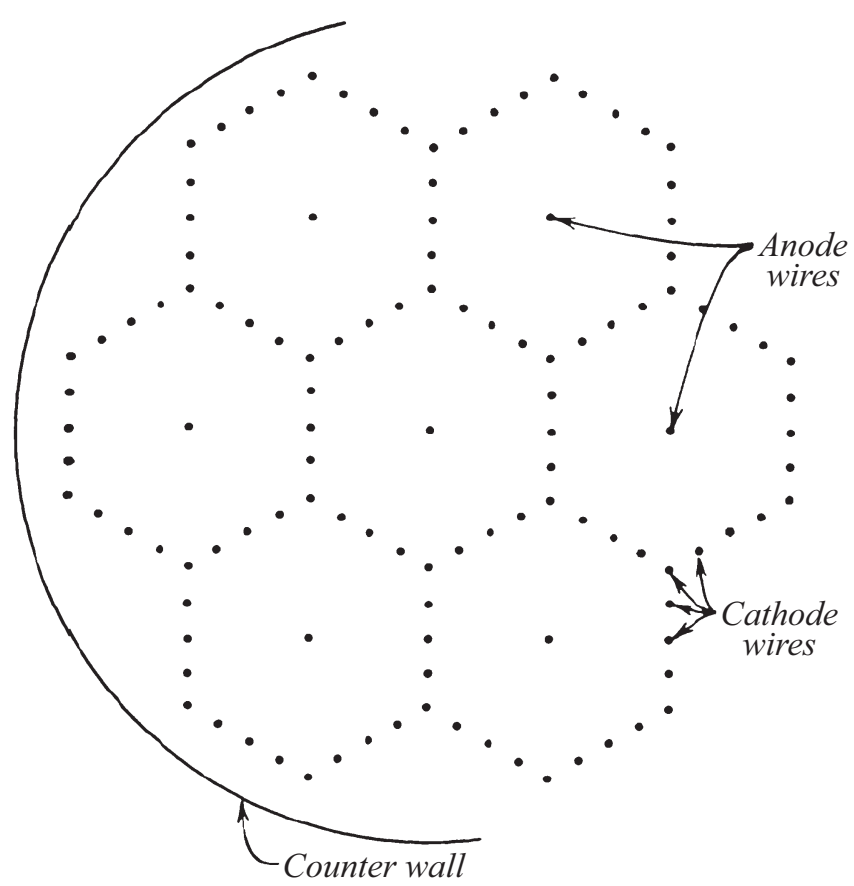

Рис. 12. Фрагмент трехслойной проволочной структуры с ячейками анод-катод, размещенными в гексагональной геометрии на пути нейтронов [20].

гексагональной геометрии (рис. 12). Ячейки заполняют весь зазор по пучку нейтронов $t=12 \mathrm{~mm}$. Здесь путь дрейфа электронов до ближайшей анодной проволочки составляет 3-5 mm, такой детектор обладает бо́льшим быстродействием и лучшим временны́м разрешением по сравнению с обычной MWPC (рис. 5). Недостатком метода является большое число каналов электроники, но в настоящее время с развитием ASIC (Application Specified Integrated Circuit) такое техническое решение является вполне приемлемым.

Уровень разработок позиционно-чувствительных детекторов ТХН, созданных в ОИЯИ ${ }^{12}$ с газовым конвер-

\footnotetext{
${ }^{12}$ Объединенный институт ядерных исследований, Дубна.
} 
тором ${ }^{3} \mathrm{He}$, был обстоятельно представлен в сообщении 2018 г. [21], но методика принципиально не отличается от [14-17]. Работа [22] является примером того, какое большое внимание уделяется системам регенерации газовой смеси с дорогостоящим изотопом ${ }^{3} \mathrm{He}$.

В отличие от типовой конструкции MWPC с тремя проволочными электродами, представленной на рис. 5, в работах $[23,24]$ применено пять электродов (рис.12). Дополнительные дрейфовые электроды введены для того, чтобы считывание сигналов с катодов производилось относительно нулевого потенциала. Учитывая, что на корпусе нулевой потенциал, а на аноде установлено положительное напряжение, на двух введенных дрейфовых электродах напряжение должно быть отрицательным, тогда на основных катодах, которые используются для измерения $X$ и $Y$ координат при помощи интегральных линий задержки, можно установить нулевое напряжение. Сравним газовое усиление MWPC в работе [24], равное 220, с газовым усилением $\sim 20$ в камере с пропаном [14]. Увеличение усиления почти на порядок привело к дополнительным флуктуациям и расширению амплитудного спектра, приведенного на рис. 13

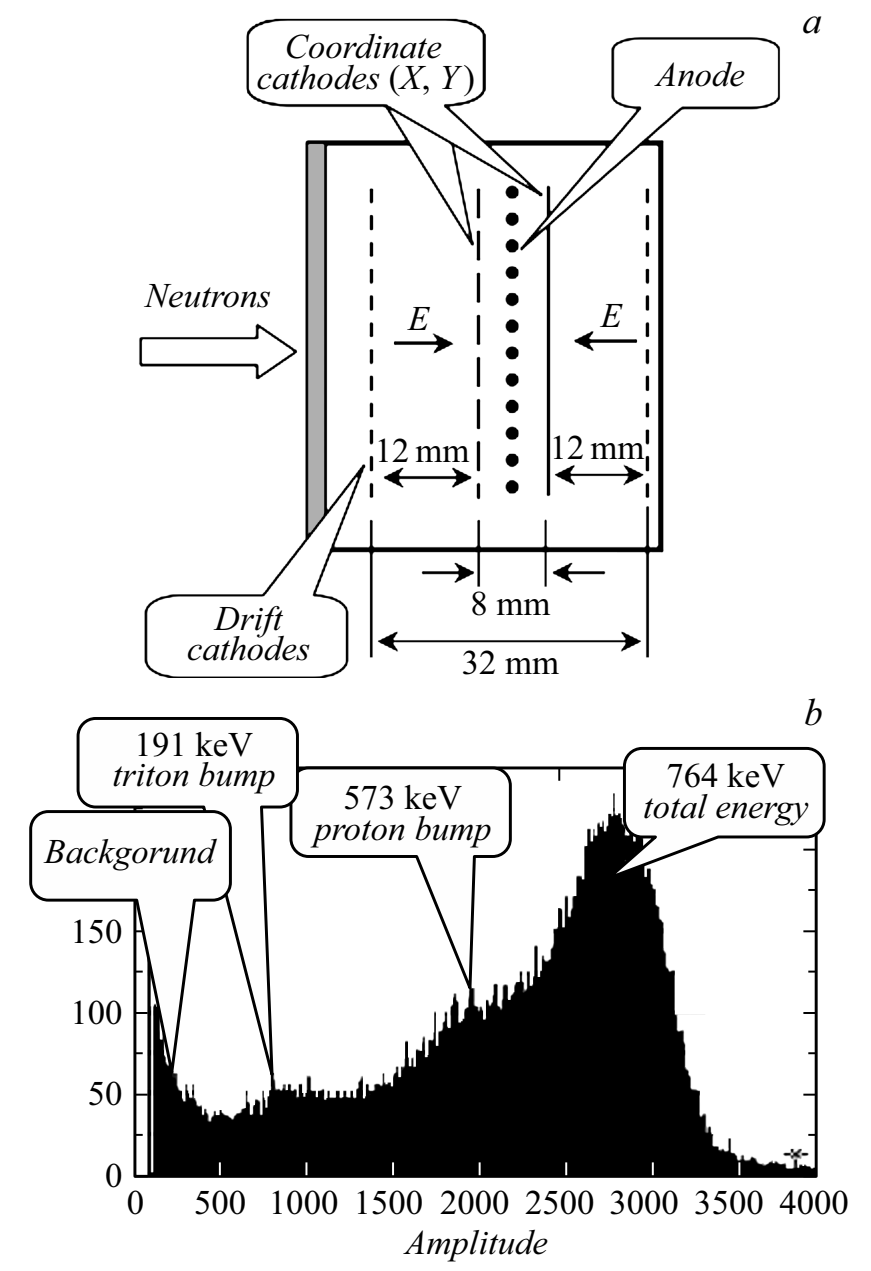

Рис. 13. $a-$ схема двухкоординатного позиционночувствительного детектора ТХН на МWPC с пятью электродами; $b$ - измеренный амплитудный спектр [24].

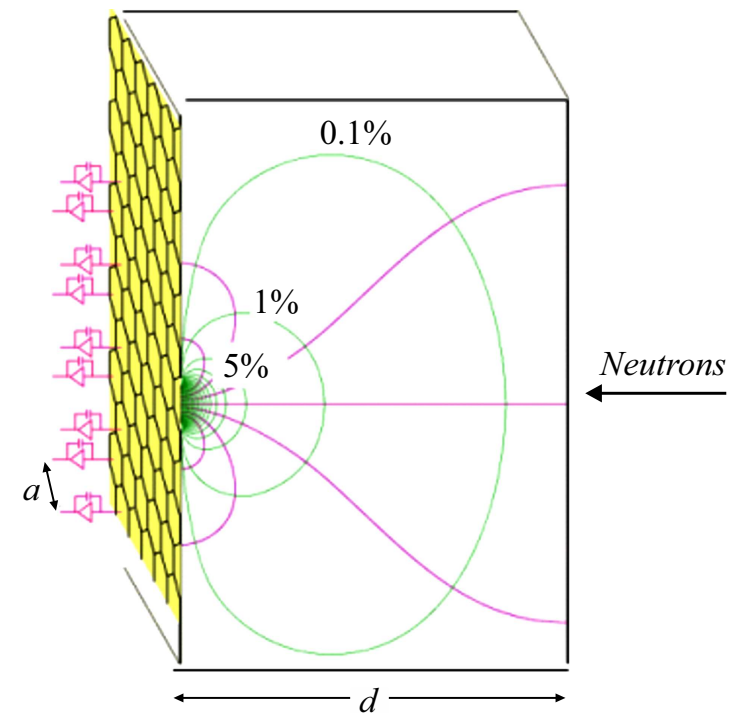

Рис. 14. Электрод многоканальной ионизационной камеры без сетки Фриша: первичный заряд собирается преимущественно на одном или двух смежных анодных пэдах [27].

$(\lambda=9 \AA)$. Показанные участки на спектре с характерными энергиями 191 и $573 \mathrm{keV}$ соответствуют полной или частичной потере одного из фрагментов реакции (1) эффект окна ${ }^{13}$, а значит, и к дополнительной ошибке в координате нейтрона, измеряемой по центру тяжести заряда. К этому эффекту добавляются потери электронов, образовавшихся между корпусом и дрейфовым электродом. К дополнительной потере первичных электронов на прилипание приводит использование в качестве добавки к гелию электроотрицательного газа $\mathrm{CF}_{4}$.

\section{Пэдовые детекторы, работающие в режиме ионизационной камеры без сетки Фриша}

В ионизационном режиме достигается наилучшее энергетическое разрешение, так как флуктуации, сопровождающие усиление в газе, здесь отсутствуют, необходимо лишь собрать первичный заряд. Кроме того, детектор без усиления исключительно стабильный - дополнительное достоинство ионизационной камеры. В пропорциональном режиме коэффициент газового усиления следует за колебаниями $P / T(P-$ атмосферное давление, $T$ - температура окружающей среды). Подчеркнем также, что в ионизационном режиме исключены пробои в газе, а также существенно снижается радиационное старение детектора с образованием и накоплением радикалов.

\footnotetext{
13 Треки фрагментов реакции (1) касаются стенок корпуса, при этом часть первичных электронов теряется, поэтому уменьшается амплитуда сигнала, а в амплитудном спектре появляется хвост, простирающийся от основного пика до нуля - эффект окна.
} 

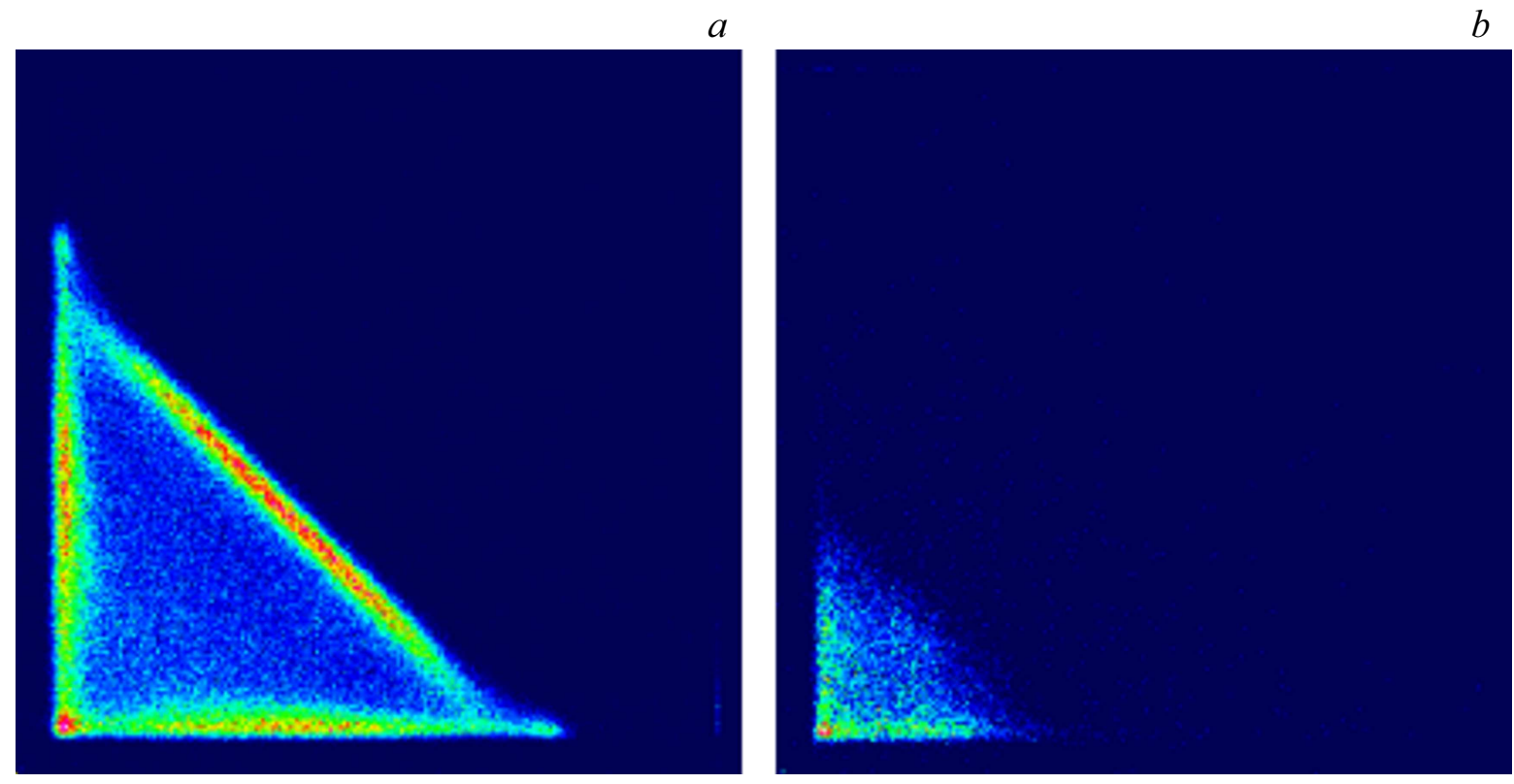

Рис. 15. $a$ - распределение амплитуд импульсов на двух смежных; $b-$ двух несмежных анодных пэдах камеры при различной ориентации первичных треков [27].

\section{Large neutron pixel detector data flow}

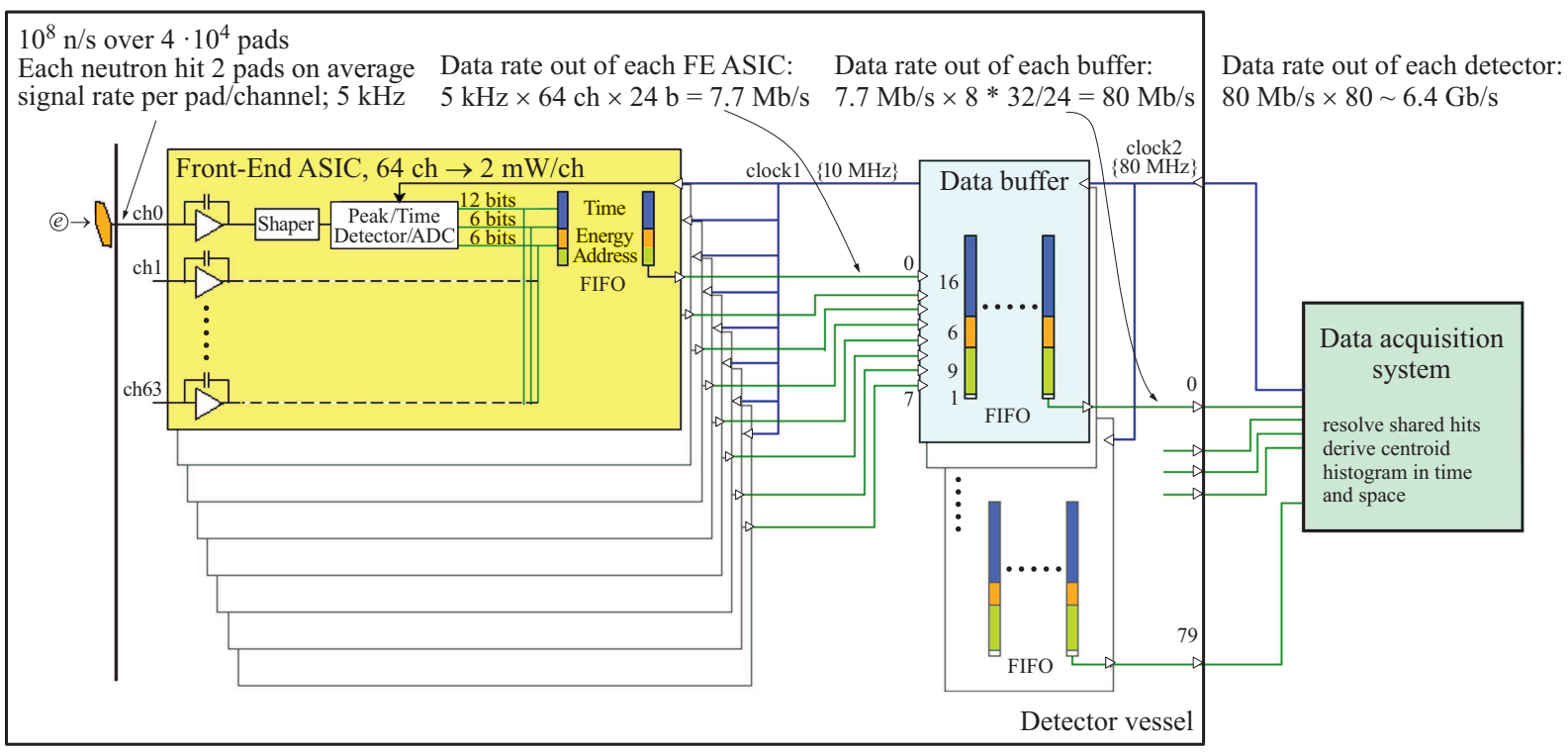

Рис. 16. Особенность разработки: 40 тысяч каналов электроники размещены в газовом объеме герметичного корпуса [5].

Рассмотрим двухкоординатный позиционно-чувствительный детектор с ионизационной камерой с единичным усилением без сетки Фриша, созданный в BNL [25-27]. Здесь первичный заряд при дрейфе к анодным пэдам собирается преимущественно на одном или двух смежных пэдах (рис. 14). Дискриминацией импульсов по уровню и соответствующей логической схемой можно быстро определить, где находится центр тяжести заряда: напротив пэда или между смежными пэдами (рис. 15). Метод позволил улучшить пространственное разрешение в 2 раза, так как регистрируется либо центр пэда, либо середина между пэдами [26]. Оптимальное давление пропана определялось программой $\mathrm{SRIM}^{14}$. С пэдами $5 \mathrm{~mm}$ был создан детектор с большой площадью $1 \times 1 \mathrm{~m}$ для дифрактометра малоуглового рассеяния нейтронов SANS (Small Angle Neutron Scattering)

\footnotetext{
${ }^{14}$ SRIM - The Stopping and Range of Ions in Matter, http://www.srim.org/
} 


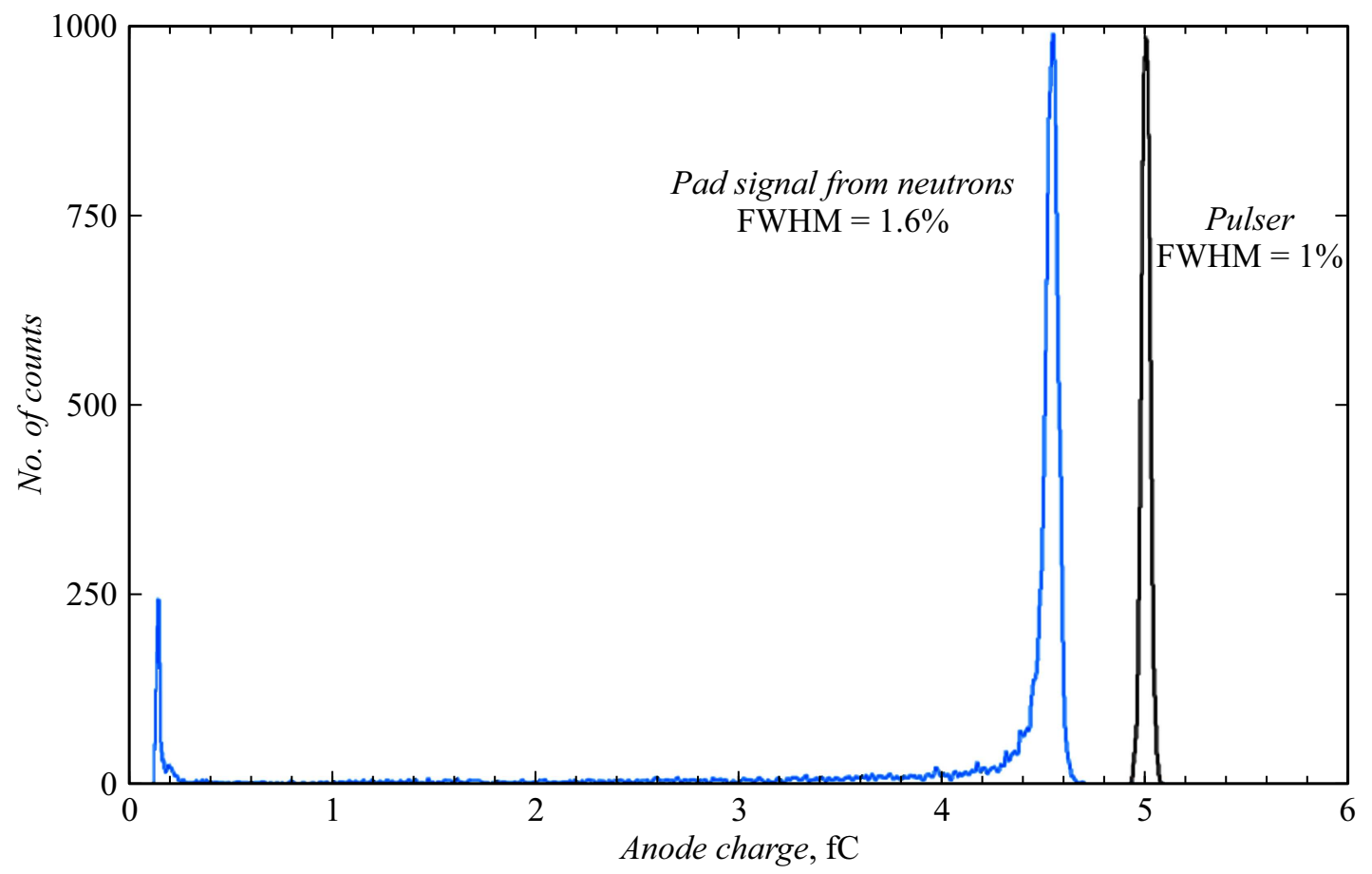

Рис. 17. Амплитудный спектр с разрешением 1.6\% (FWHM), измеренный на нейтронах с одного пэда ионизационной камеры; пик справа - генераторная линия $5 \mathrm{fC}$ с разрешением 1\% (FWHM) [5].

с рекордно высокой скоростью набора событий $10^{8} \mathrm{~s}^{-1}$ $\left(10^{5} \mathrm{~s}^{-1} / \mathrm{pad}\right)$. Электроника детектора была выполнена на 64-канальных чипах ASIC и содержала в каждом канале наряду с предусилителем и усилителем-формирователем также ADC. Платы с электроникой - 40 тысяч каналов $(200 \times 200$ пэдов) - были установлены внутри корпуса детектора, наполненного двухкомпонентной смесью ${ }^{3} \mathrm{He} / \mathrm{C}_{3} \mathrm{H}_{8}$ (3/2 bar), и такое техническое решение не привело к отравлению рабочего газа. Из корпуса детектора было выведено наружу через герметичные вводы всего 80 линий для передачи цифровых данных в последовательном коде, по которым информация передавалась в компьютер со скоростью $6.4 \mathrm{~Gb} / \mathrm{s}$ (рис. 16).

Амплитудный спектр с одного пэда (рис. 17), измеренный в ионизационном режиме, выглядит почти монолинией $(764 \mathrm{keV})$ с незначительным эффектом окна. Для калибровки шкалы в единицах заряда показана генераторная линия $5 \mathrm{fC}$ с разрешением 1\%. Видно, что при времени формирования $2 \mu \mathrm{s} \mathrm{ENC}=312 \mathrm{e}$. Время формирования выбрано большим для того, чтобы минимизировать последовательный шум, зависящий от емкости $C_{D}-$ емкости одного пэда. Шумовой счет с одного канала составлял при этом один импульс в час.

Стриповый съем информации, который в отличие от пэдового приводит к существенному уменьшению числа каналов электроники, в ионизационном режиме работы камеры невозможен. Существенное увеличение емкости стрипа по сравнению с емкостью пэда приведет к тому, что сигнал от первичного заряда на выходе усилителя утонет в шумах.

\section{Позиционно-чувствительные детекторы на газонаполненных микростриповых счетчиках - MSGC}

В 1988 г. была опубликована важная в концептуальном плане работа [28] из ILL, в которой для регистрации ТХН был впервые предложен микростриповый детектор - MSGC и показаны его свойства. Новый детектор был выполнен по технологии фотолитографии на подложке из оптического стекла ${ }^{15}$ толщиной $0.5 \mathrm{~mm}$ [28]. В MSGC умножение заряда электронов происходит вблизи тонкого печатного стрипа-анода, ширина и толщина которого такие, как диаметр анодной проволочки в MWPC $\sim 10 \mu \mathrm{m}$ (рис. 18). Главной особенностью конструкции MSGC является то, что расстояние от анода до катода уменышено до $50 \mu \mathrm{m}$ (в МWPC это - миллиметры). В результате положительные ионы намного быстрее удаляются из зоны анод-катод, как следствие, быстродействие MSGC увеличивается почти в 100 раз. С таким детектором достигнута скорость счета $10^{7} \mathrm{~s}^{-1}$, и ограничением счета является не детектор, а мертвое время канала регистрации из-за длительности импульсов с усилителей. Кроме того, при шаге стрипов в 10 раз меньшем шага анодных проволочек MWPC, соответственно в 10 раз улучшено пространственное разрешение, шаг $100 \mu \mathrm{m}$ здесь - не проблема. Выше отмечалось, что в MWPC шаг проволочек вносит ос-

\footnotetext{
15 Стекло фирмы Schott S8900 в отличие от Desag D263 и Corning 7740 электрически стабильное, с которым не замечено изменений характеристик MSGC.
} 

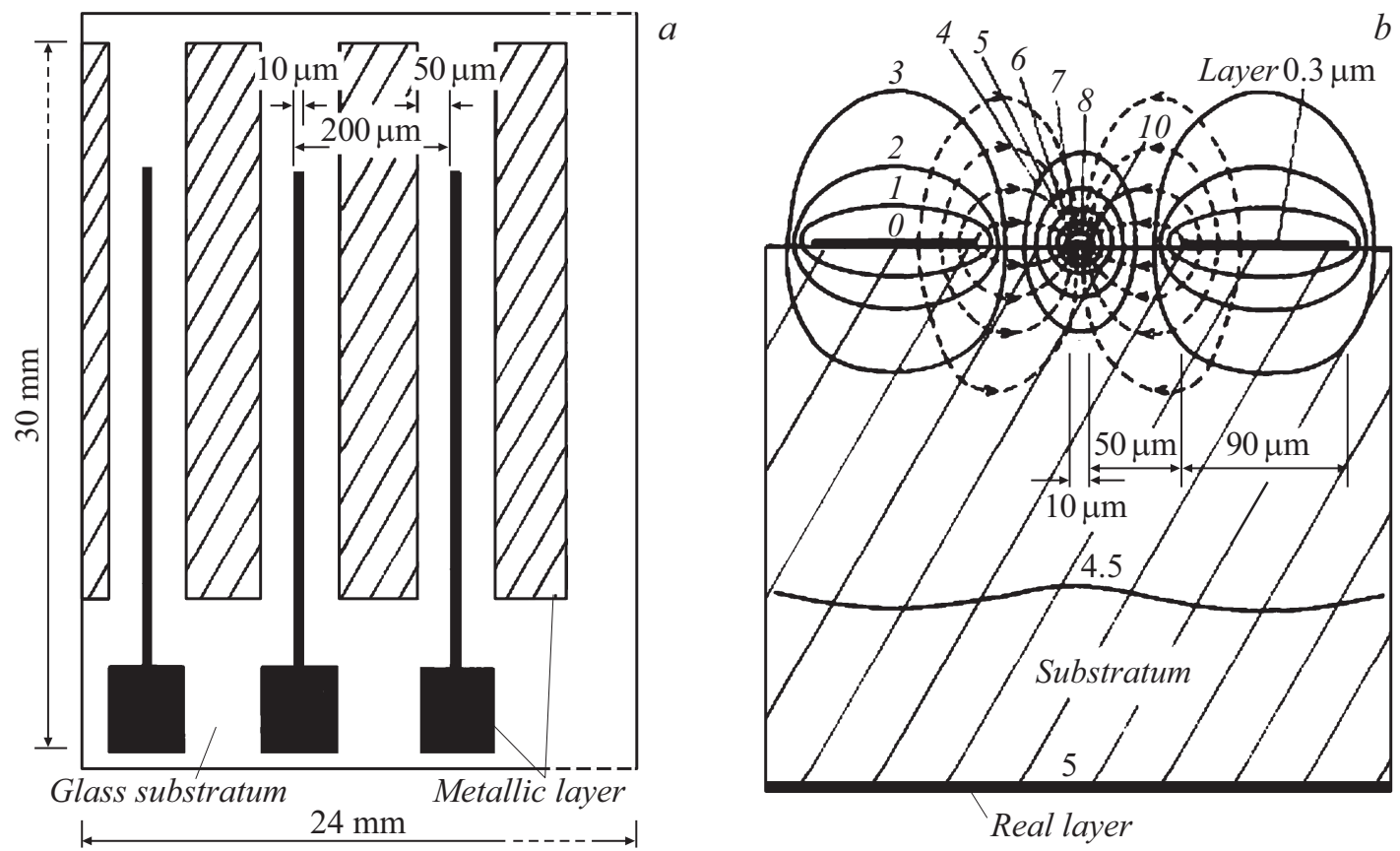

Рис. 18. $a$ - схема микрострипового детектора MSGC: печатные стрипы на подложке из оптического стекла; $b-$ линии электрического поля [28].

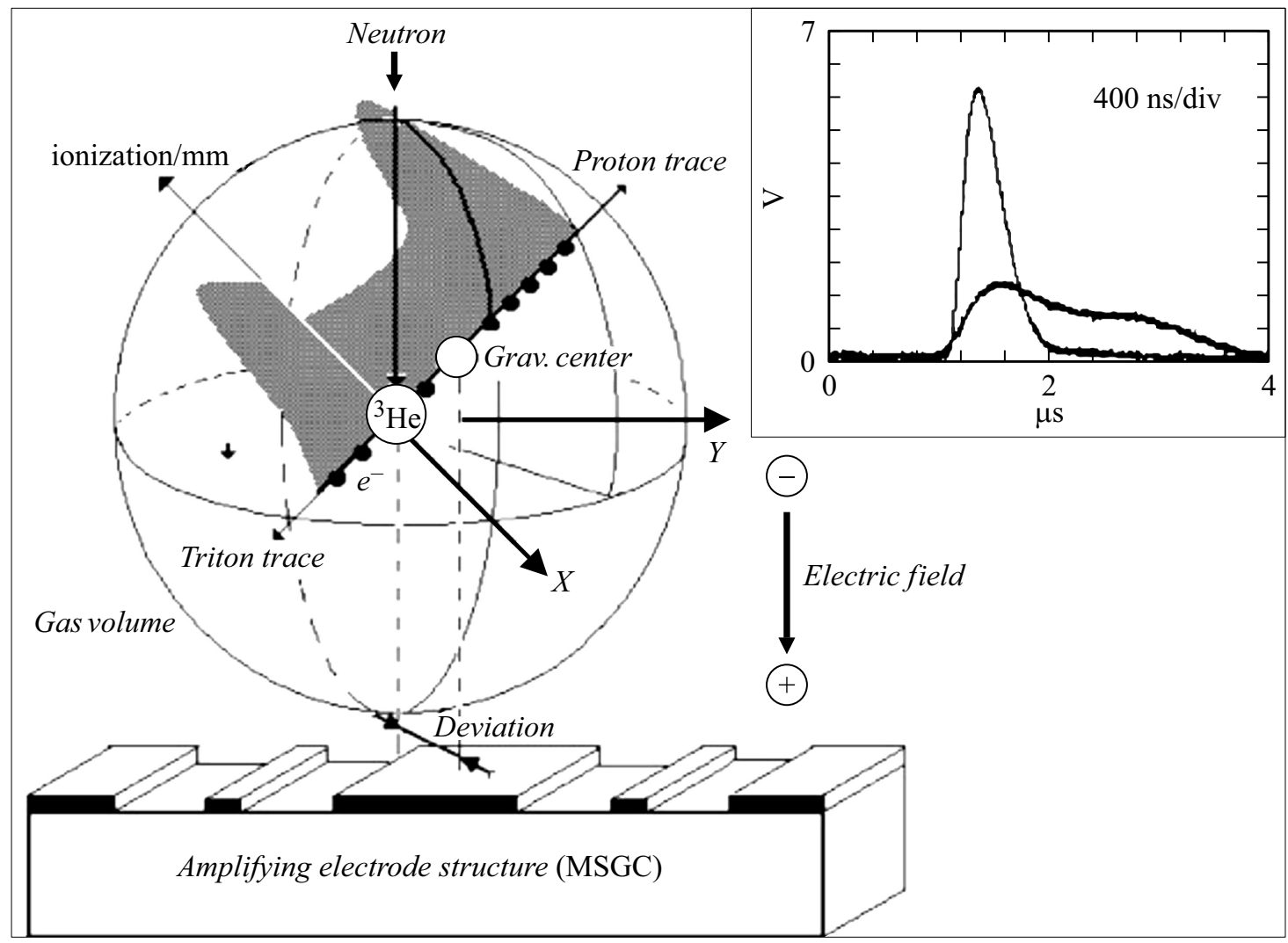

Рис. 19. В форме шара показана область отклонений центра тяжести от истинной точки захвата нейтрона ядром гелия. По форме импульсов (справа) можно судить об ориентации треков: узкий импульс с бо́льшей амплитудой соответствует ориентации параллельно, а широкий с меньшей амплитудой — перпендикулярно стрипам [28]. 
новной вклад в ошибку измерения координаты поперек проволочек.

По форме импульсов можно судить об ориентации треков: узкий импульс с бо́льшей амплитудой соответствует ориентации треков параллельно, а широкий с меньшей амплитудой - с наклоном или перпендикулярно стрипам, как показано на рис. 19.

На рис. 20 приведен амплитудный спектр, из которого видно, что разделение сигналов от нейтронов и гамма-фона достаточно хорошее. Показанная стрелкой энергия $192 \mathrm{keV}$ принадлежит тритону и свидетельствует о том, что протон полностью поглощен входным окном детектора - эффект окна.

При производстве MSGC стрипы наносят на стеклянную подложку напылением хрома, так как у хрома лучше адгезия к стеклу, чем у меди. Кроме того, у хрома выше электрическое сопротивление $\sim 1.5 \mathrm{k} \Omega / \square$,

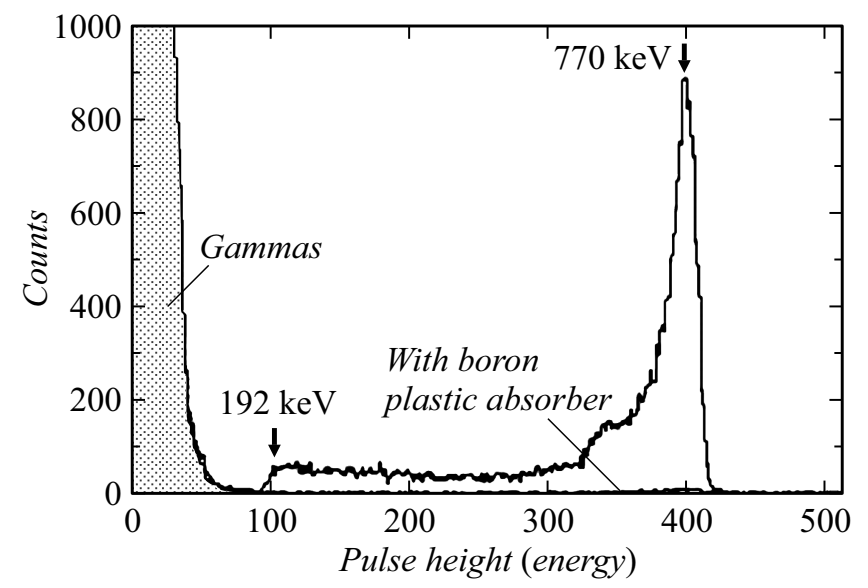

Рис. 20. Амплитудный спектр от тепловых нейтронов в микростриповом детекторе MSGC [28].

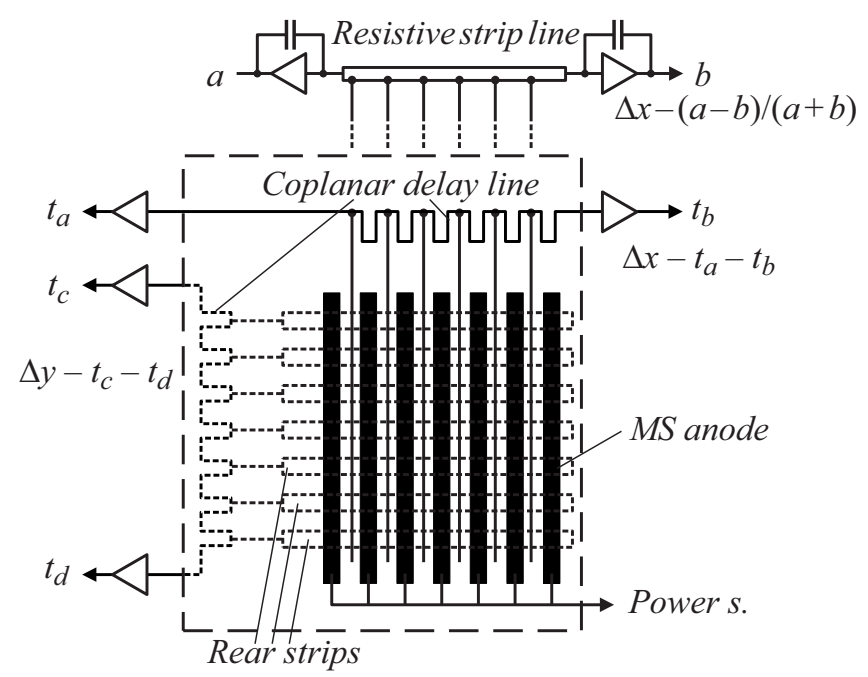

Рис. 21. Считывание координатной информации с основных и дополнительных стрипов, размещенных на противоположной стороне подложки и ориентированных ортогонально к основным стрипам [4].

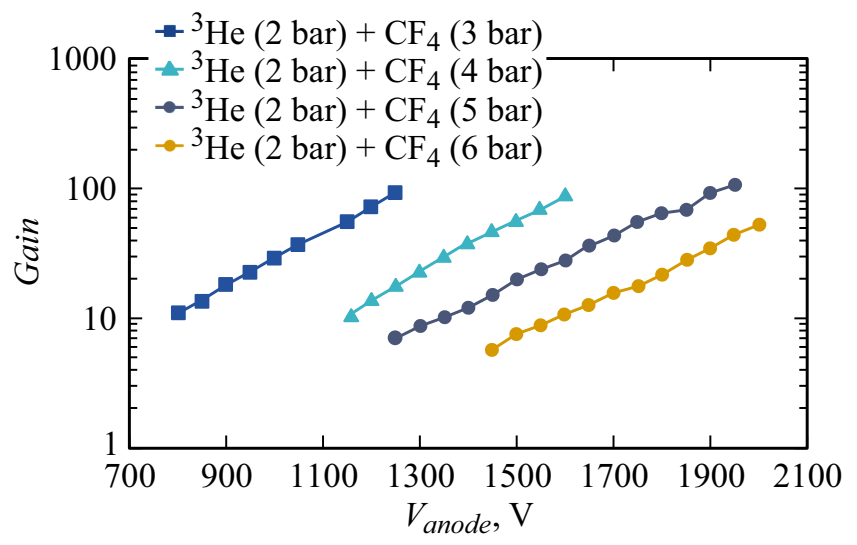

Рис. 22. Зависимости газового усиления от напряжения на стрипах MSGC для различных соотношений смеси ${ }^{3} \mathrm{He}$ и $\mathrm{CF}_{4}[29]$.

это дает для стрипа длиной $20 \mathrm{~cm} \mathrm{c} \mathrm{шириной} 10 \mu \mathrm{m}$ сопротивление $30 \mathrm{k} \Omega$ - важная величина для определения координаты делением заряда. Для исключения накопления заряда на поверхность стекла напыляют слой алмазо-подобного углерода (Diamond-Like Carbon, DLC) в виде резистивной пленки с поверхностным ${ }^{16}$ сопротивлением $\sim 10^{14} \Omega / \square$.

С размещением дополнительных стрипов на противоположной стороне подложки и ориентированных ортогонально основным стрипам, как показано на рис. 21 пунктиром, реализуется двухкоординатное считывание $X$ и $Y$. Сигналы на дополнительных стрипах имеют положительную полярность. Они наводятся движущимися положительными ионами аналогично тому, как это происходит на основных катодных стрипах MSGC, которые расположены слева и справа от анодного стрипа. На анодных стрипах наводятся сигналы отрицательной полярности. Для определения координаты сработавшего стрипа с минимальным числом каналов электроники можно подключить стрипы к секциям резистивного делителя (Resistive Division, RD) или к секциям линии задержки (Delay Line, DL), показанным на рис. 21 [4].

Автор работы [28] впервые предложил в качестве многоатомной добавки использовать фреон $\mathrm{C}_{2} \mathrm{~F}_{6}$ (тетрафторэтан) с бо́льшим, чем пропан и $\mathrm{CF}_{4}$, молекулярным весом, который при давлении 1 и 3 bar соответственно в 1.5 и 2.5 раза сокращает пробеги энергичных протонов. Заметим, что MWPC не работает с этой добавкой, так как вокруг анодной проволочки очень быстро возникает шуба положительных ионов, которые экранируют анодную проволочку, в результате чего падает амплитуда сигналов, падает загрузочная способность, чего нет в MSGC.

На рис. 22 приведены результаты измерения зависимости газового усиления от напряжения по амплитуде

\footnotetext{
16 Поверхностное сопротивление резистивной пленки толщиной $d$ не зависит от размеров квадрата и определяется отношением $R=\rho / d[\mathrm{Ohm} / \square]$, где $\rho$ - удельное сопротивление материала пленки.
} 
сигналов на анодных стрипах MSGC, полученные в ILL для различных соотношений ${ }^{3} \mathrm{He}$ и $\mathrm{CF}_{4}$ [29]. При суммарном давлении газовой смеси, изменяющемся от 5 до $8 \mathrm{bar}$, достигается газовое усиление в диапазоне 10-100. Отчетливо видно, что с увеличением концентрации $\mathrm{CF}_{4}$ приходится увеличивать напряжение для компенсации потери первичных электронов на прилипание.

В работе [29] предложена конструкция MSGC с $2 D$-считыванием координатной информации с катодными стрипами клинообразной формы, между которыми находится анодный стрип: координата $X$ определяется по номеру сработавшего стрипа, а ортогональная ей координата $Y$ - делением заряда на клиньях катодных стрипов $^{17}$.

B ILL создавались первоклассные дифракционные приборы с позиционно-чувствительными детекторами как на MWPC, так и на MSGC. За 20 лет создано более десяти дифракционных приборов, построенных на MSGC [20,30-33], которые успешно работают до настоящего времени. В качестве примера приведем дифрактометр D20. Этот дифрактометр, построенный в ILL в 1997 г. на MWPC [33], был переведен на MSGC [34]. Ha MSGC он содержит 48 модулей $127 \times 127 \mathrm{~mm} \mathrm{c}$ активной областью $80 \times 80 \mathrm{~mm}$, размещенных с зазорами между модулями $50 \mu \mathrm{m}$. Полная зона детектирования имеет длину $4.1 \mathrm{~m} \mathrm{c}$ апертурой $2 \theta=153.6^{\circ}$ и высотой $150 \mathrm{~mm}$ с расстоянием до образца $1471 \mathrm{~mm}$. Для устранения параллакса применен полигональный изгиб детектирующей поверхности, (рис. 23). В новом дифрактометре D20 используется газовая смесь ${ }^{3} \mathrm{He} / \mathrm{CF}_{4}$ (3.1/0.8 bar). Добавка $\mathrm{CF}_{4}$ увеличивает скорость дрейфа электронов, поэтому толщина конвертора увеличена до $t=5.3 \mathrm{~cm}$, что позволило уменьшить давление гелия и уменьшить толщину входного окна корпуса. Для нейтронов с $\lambda=0.8$ и $2.4 \AA$ получена эффективность регистрации 60 и 90\% соответственно. Всего в дифрактометре 1536 детекторных каналов, размещенных через $0.1^{\circ}$, работающих независимо с мертвым временем $5 \mu \mathrm{s}$ каждый. Скорость набора событий достигает $10^{6} \mathrm{~s}^{-1}$ при потоке нейтронов на образце $10^{8} \mathrm{~ns}^{-1} \mathrm{~cm}^{-2}$. На набор одной дифрактограммы затрачивается $200 \mathrm{~ms}$. Запись дифрактограммы в компьютер производится за $100 \mathrm{~ms}$, и это время совмещается с набором следующей дифрактограммы.

Следует отметить, что подложка из стекла необязательна для MSGC, известны работы, где MSGC успешно работает на подложке из полиимидной пленки (каптона) толщиной $20 \mu \mathrm{m}[35,36]$. Для определения координаты по номеру каждого индивидуального стрипа требуется много каналов электроники, но это не является проблемой в настоящее время. При таком способе считывания информации уменьшается шум благодаря меньшей емкости на входе усилителя и, как следствие, улучшается энергетическое разрешение и разделение нейтронов и гамма-фона. На рис. 24 приведена

\footnotetext{
${ }^{17}$ См. также A. Oed et al. Nucl. Instr. and Meth. A 416 (1998) 263-266.
}

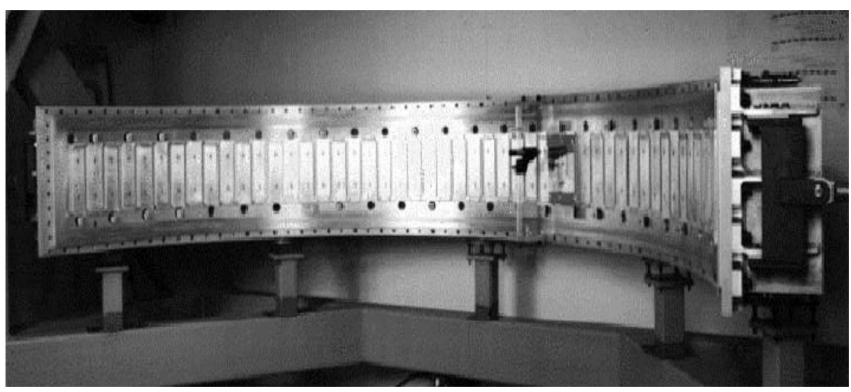

Рис. 23. Детектор кольцевого дифрактометра D20, выполненный на MSGC из 48 модулей [34].

блок-схема 256-канальной системы съема информации с MSGC-детектора [36] с определением координат $X$ и $Y$ по номерам сработавших стрипов. Детектор работает на бинарной смеси ${ }^{3} \mathrm{He} / \mathrm{CF}_{4}$, которой свойственно высокое быстродействие.

В работе [37] предложена оригинальная идея MSGC с гибкой подложкой из каптона. Гибкая подложка позволила согнуть и вмонтировать MSGC в металлическую трубку диаметром $5 \mathrm{~mm}$ и длиной $640 \mathrm{~mm}$. Напомним, что у стандартной проволочной трубки пространственное разрешение вдоль трубки $\sim 1 \mathrm{~cm}$. Новая трубка позволила улучшить разрешение вдоль трубки в шесть раз - до $1.6 \mathrm{~mm}$, при этом сохранено высокое быстродействие, присущее MSGC, в 100 раз превышающее быстродействие проволочной трубки. Стоит рассмотреть подробнее, как устроена и работает новая схема MSGC, представленная на рис. 25. Слева и справа от анодного стрипа (Anode) введено по паре стрипов (Grid 1, Grid 2), расположенных параллельно аноду. За ними введено еще по паре катодных стрипов Cathode 1, Cathode 2 (Local Cathode) и Cathode 3, Cathode 4 (Global Cathode), выполненных в форме меандра. Стрипы Cathode 1, Cathode 2 имеют переменный шаг на интервале $32 \mathrm{~mm}$ вдоль трубки, а стрипы Cathode 3, Cathode 4 - постоянный шаг на том же интервале. Такая модуляция шага Local pitch относительно Global pitch позволяет определить координату путем измерения амплитуды импульсов, которые наводятся синфазно на всех катодных стрипах дрейфующими положительными ионами.

Важным в концептуальном отношении является наблюдение в 2004 г. световых сигналов в MSGC в бинарной смеси ${ }^{3} \mathrm{He} / \mathrm{CF}_{4}$ - первичной люминесценции [38], позволяющее ввести в практику позиционно-чувствительных детекторов время $T_{0}-$ момент захвата нейтрона ядром конвертора (рис. 26). Первичное свечение происходит в момент захвата нейтрона ядром гелия даже без приложенного к электродам детектора напряжения. Возбуждение снимается сбросом фотонов с электронных оболочек возбужденных атомов $\mathrm{CF}_{4}$. В процессе лавинного умножения вблизи анода MSGC возникает вторичное свечение - электролюминесценция (см. два импульса на рис. 26, разнесенных во времени [20]). 


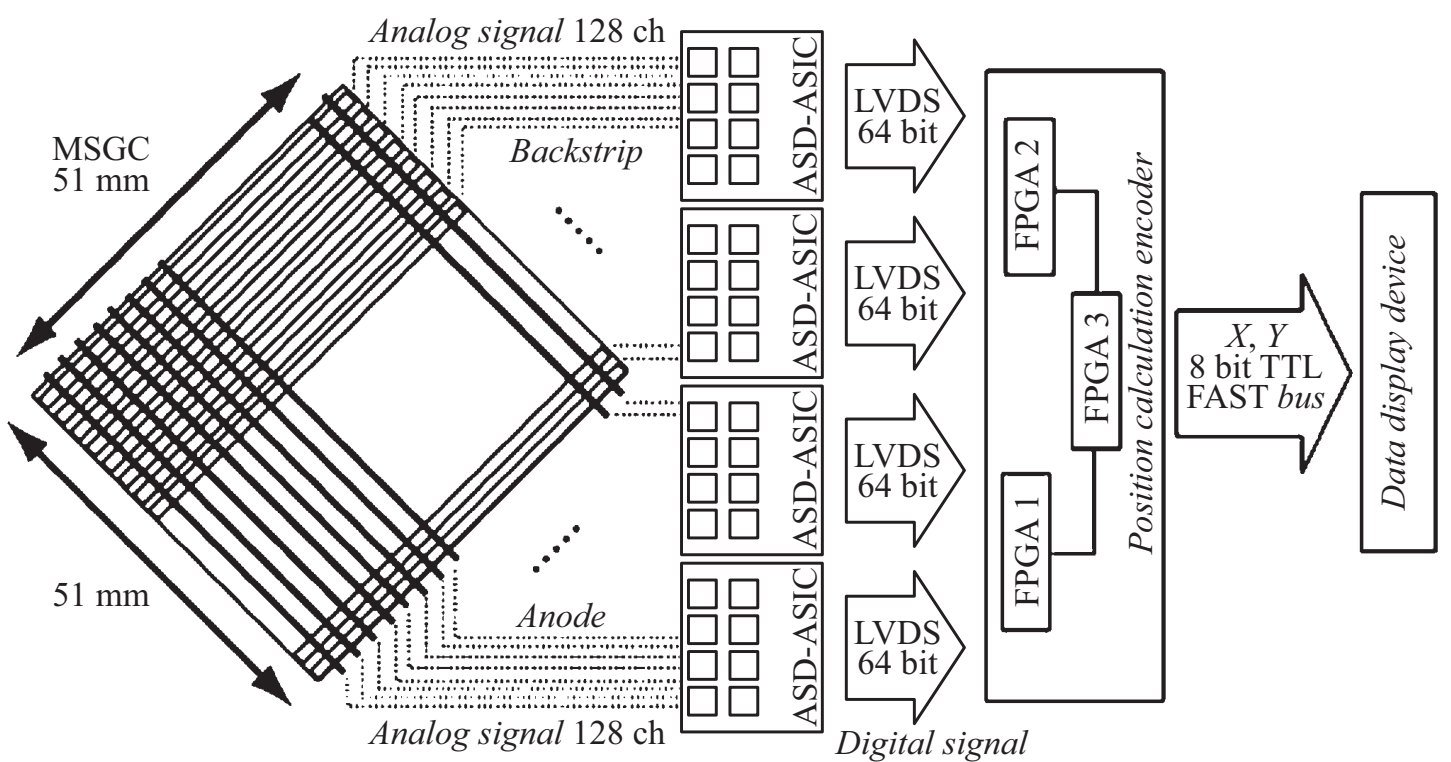

Рис. 24. Основные блоки многоканальной системы считывания координатной информации по номерам сработавших стрипов MSGC [36].

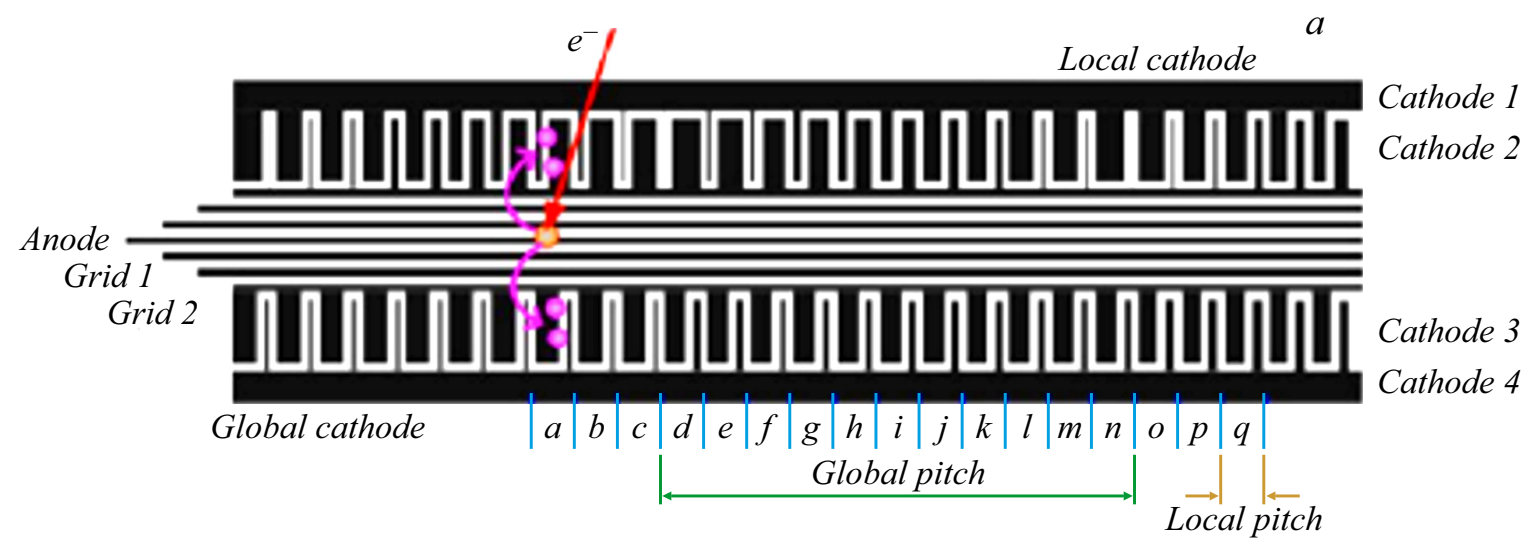

\begin{tabular}{|c|c|c|c|c|c|c|c|c|c|c|c|c|c|c|c|}
\hline & $a$ & $b$ & \begin{tabular}{l|c}
$c$ & $c$ \\
\end{tabular} & $d \mid c$ & $e f$ & $g$ & $h$ & $i$ & $j$ & $k$ & \begin{tabular}{l|l}
$l$ & 1 \\
\end{tabular} & $n 1$ & $n$ & 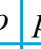 & 9 \\
\hline Cathode 1 & $\boldsymbol{\Lambda}$ & $\Lambda$ & $a$ & رام & 1 & $\Lambda$ & & $\Lambda$. & $\Lambda$. & $\Lambda$. & $\Lambda$ & & & & 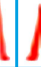 \\
\hline Cathode 2 & & & $\Lambda$ & & & $\Lambda$ & & $\Lambda$. & $\Lambda$ & $\Lambda$. & $\mathbf{\Lambda}$ & $\mathbf{A}$ & & & \\
\hline Cathode 3 & & & d & & & & & $A$ & $\Lambda$ & 1 & $\Lambda$ & & & d. & \\
\hline Cathode 4 & & & & & & & & & & & & & & & \\
\hline
\end{tabular}

$b$

Рис. 25. $a$-конструкция MSGC на гибкой подложке из каптона длиной $640 \mathrm{~mm}$ и шириной $15 \mathrm{~mm}$ для размещения внутри трубки; $b-$ амплитуда импульсов на катодных стрипах структуры зависит от места прохождения нейтрона [37].

Первый импульс меньшей амплитуды соответствует первичному свечению, второй - лавинному умножению. Сдвиг второго сигнала по времени обусловлен дрейфом первичных электронов в область умножения MSGC. $\mathrm{B}$ спектральной области излучение $\mathrm{CF}_{4}-$ первичное и вторичное - практически не отличается, два пика находятся в диапазоне длин волн ${ }^{18} 250-650$ nm. С увеличением давления $\mathrm{CF}_{4}$ выход фотонов увеличивается [39].

\footnotetext{
${ }^{18}$ Margato L. Jornadas LIP, April 21-23, 2012, Lisbon, Portugal.
} 


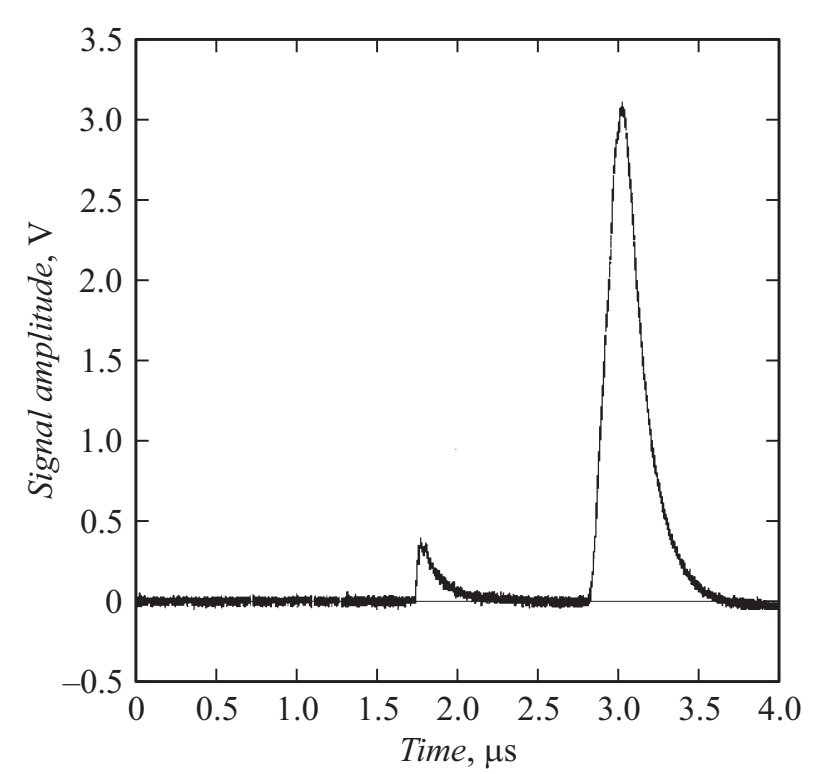

Рис. 26. Сигналы от люминесценции, сопровождающей захват нейтрона ядром гелия, зарегистрированные ФЭУ в смеси ${ }^{3} \mathrm{He} / \mathrm{CF}_{4}$ (слева), и от электролюминесценции вблизи анода MSGC [20].

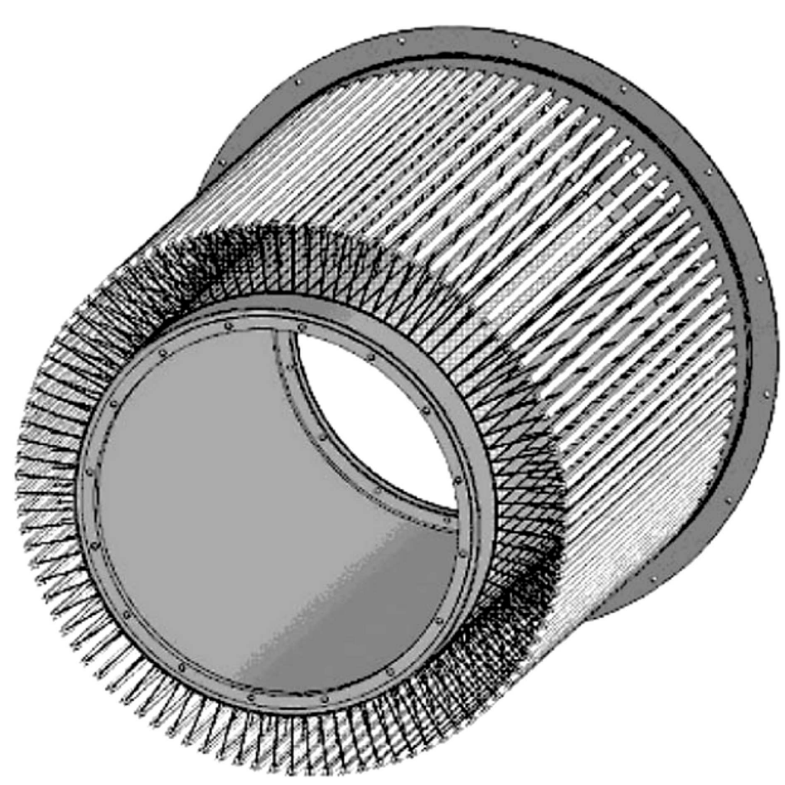

Рис. 27. Проект $4 \pi$-дифрактометра с регистрацией трех координат $X, Y, Z$ центра тяжести первичного заряда в зазоре между смежными пластинами MSGC: $X, Y$ измеряются по номерам сработавших стрипов MSGC, $Z$ - по времени дрейфа заряда до MSGC, отсчитываемого от первичной световой вспышки [20].

B ILL разработан интересный проект детектора для кольцевого дифрактометра LADI с $4 \pi$-геометрией с 576 счетчиками MSGC, в котором регистрируется первичная люминесценция. Это позволило регистрировать три координаты точки захвата нейтрона ядром гелия (рис. 27) [20]. MSGC выполнены с размерами пластин $6.5 \times 5 \mathrm{~cm}$ на оптическом стекле Schott S8900 толщиной $0.4 \mathrm{~mm}$. Зазоры $\sim 1 \mathrm{~cm}$ между парой счетчиков MSGC просматриваются с двух сторон фотоумножителями ${ }^{19}$, регистрирующими первичное свечение и позволяющими по времени дрейфа электронов в область умножения определить $Z$-координату. Ожидается высокая эффективность (рис. 2) за счет большой толщины слоя гелия $(t=5 \mathrm{~cm})$ на пути нейтронов: $\varepsilon=70 \%$ для $\lambda=1 \AA$ при относительно невысоком парциальном давлении гелия $p=3$ bar, а пространственное разрешение по $X$ и $Y-$ не хуже $0.5 \mathrm{~mm}$ при добавке многоатомного газа $\mathrm{CF}_{4} 6$ bar. Независимость пары счетчиков - MSGC и ФЭУ позволяет за счет параллелизма получить высокую скорость счета мультидетектора.

\section{Применение микроструктурных детекторов нового поколения - MPGD для регистрации TXH}

Хотя MSGC изобретен 30 лет назад, его потенциальные возможности еще не исчерпаны. Отметим, что изобретение MSGC послужило толчком к бурному развитию нового класса детекторов, названных микроструктурными - $\mathrm{MPGD}^{20}$, хотя MSGC не вошел в это семейство. Причиной тому является его ненадежность в экспериментах в области физики высоких энергий, когда требуется газовое усиление $\sim 10^{4}$. При таком усилении сильноионизирующие газ частицы, которые могут рождаться в элементах конструкции детектора, вызывают электрические пробои в области умножения настолько мощные, что приводят к обрыву анодного стрипа MSGC.

В составе MPGD выделяются два основных класса детекторов:

- $\mathrm{GEM}^{21}$ с разновидностями [40];

- MicroMeGas c разновидностями [41] - аббревиатура от MicroMesh Gaseous (другое краткое обозначение - MM).

Оба класса MPGD способны заменить MSGC.

На рис. 28 приведен детектор на основе классического GEM, который можно применить для регистрации ТХН. Он содержит дрейфовый (рабочий) зазор и индукционный зазор, между которыми установлен собственно GEM - перфорированный элемент с двумя электродами, размещенными на фольгированной полиимидной пленке (каптоне) со сквозными микроотверстиями. В классическом GEM отверстия диаметром 50-70 $\mu$ расположены в гексагональной геометрии с шагом $140 \mu\left(\sim 50\right.$ отверстий на $\left.1 \mathrm{~mm}^{2}\right)$, толщина каптона

\footnotetext{
${ }^{19}$ Например, ФЭУ hamamatsu R292 со спектральной областью $185-900 \mathrm{~nm}$.

20 http:mpgd.web.cern.ch/mpgd/

${ }^{21}$ Не путать устоявшуюся в англоязычной литературе аббревиатуру GEM - Gaseous Electron Multiplier с известной аббревиатурой нейтронного дифрактометра на реакторе ISIS: GEM - General Materials Diffractometer
} 


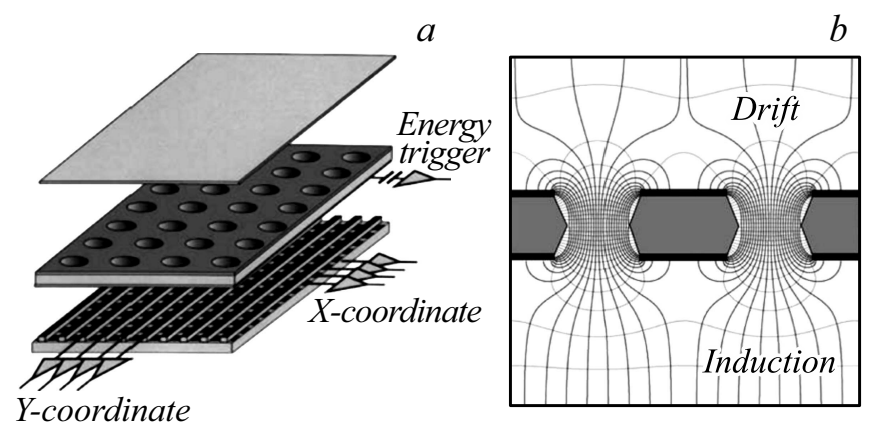

Рис. 28. $a-$ детектор на основе GEM с дрейфовым и индукционным зазорами; $b$ - электрическое поле в отверстиях GEM [40].

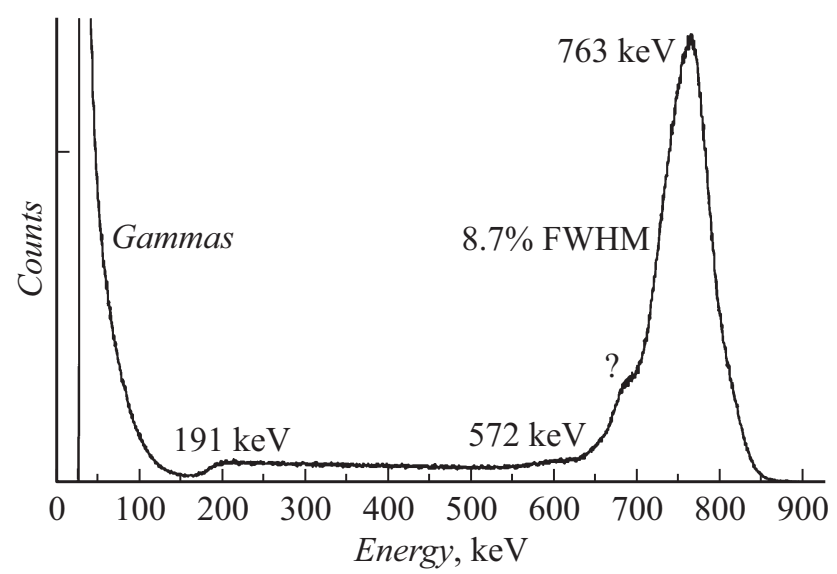

Рис. 29. Амплитудный спектр от тепловых нейтронов в детекTope GEM, полученный на смеси ${ }^{3} \mathrm{He} / \mathrm{CF}_{4}(0.4 / 1$ bar) $[42,43]$.

$50 \mu$, толщина меди на электродах $5 \mu$. Образованный в рабочем зазоре детектора первичный заряд электронов дрейфует к отверстиям, в которых лавинно умножается. Вторичные электроны выходят из отверстий в индукционный зазор и, двигаясь в направлении считывающих стрипов, наводят на них сигналы отрицательной полярности. Положительные ионы из отверстий двигаются в обратном направлении и также индуцируют сигналы отрицательной полярности на стрипах, но они проходят на порядок меньший путь в отверстиях, чем электроны в индукционном зазоре, поэтому их вклад в амплитуду сигналов незначителен.

На рис. 29 приведен амплитудный спектр, полученный от TXH в GEM-детекторе, наполненном двухкомпонентной смесью ${ }^{3} \mathrm{He} / \mathrm{CF}_{4}$ (0.4/1.0 bar) и выполненном конструктивно, как показано на рис. 28 , с рабочим зазором $14 \mathrm{~mm}$ и индукционным зазором $3 \mathrm{~mm}[42,43]$. Если сравнить этот спектр с рис. 20 (MSGC), то видно, что спектры довольно близки. Ориентация треков протонтритон относительно стрипов GEM, приводит к разной амплитуде и длительности сигналов, опять же аналогично MSGC. Каждое отверстие GEM - независимый попорциональный счетчик, но GEM отличает изотропность размещения умножающих элементов - отверстий, а значит, одинаковое пространственное разрешение вдоль осей $X$ и $Y$, чего нет в MSGC и MWPC.

Литературы по применению GEM в дифрактометрах ТХН пока нет, но, как было показано выше, есть успешное применение MSGC в этой области, а GEM не уступает MSGC. Отметим, что для регистрации TXH достаточно усиления 10 , так как сигналы на стрипах в этом детекторе наводит движущийся в индукционном зазоре заряд электронов, в то время, как в MSGC и MWPC - заряд положительных ионов. Скорость дрейфа положительных ионов в 1000 раз меньше, чем электронов, и это приводит к баллистическому дефициту - за одинаковое время интегрирования в GEM регистрируется существенно бо́льший заряд [11], а значит, меньшего газового усиления по сравнению с MSGC и MWPC достаточно, чтобы на входе дискриминатора получить одинаковые по амплитуде импульсы. Усиление 10 в GEM (рис. 30) примерно соответствует усилению 100 в MSGC (рис. 22).

Среди других MPGD представляется интересной работа [44], в которой для регистрации ТХН используется детектор MHSP (Micro Hole Strip Plate) - комбинация GEM и MSGC на одной подложке (рис. 31). В этой структуре лавинное умножение электронов происходит в две стадии: сначала в отверстии, а затем на микрострипе, размещенном между отверстиями с противоположной стороны подложки. В цитируемой работе на MHSP был создан детектор ТХH, наполненный трехкомпонентной смесью: ${ }^{3} \mathrm{He}$ в качестве конвертора с добавкой аргона и ксенона для уменьшения пробегов протона и тритона. Экспериментально показано, что при изменении парциального давления гелия в пределах $1-6$ bar с добавкой аргона (3 bar) и небольшого количества ксенона $(50 \mathrm{mbar})$ достигается стабильная работа детектора MHSP при газовом усилении, достигающем 2000 (рис. 32). Подчеркнем, что для надежной регистра-

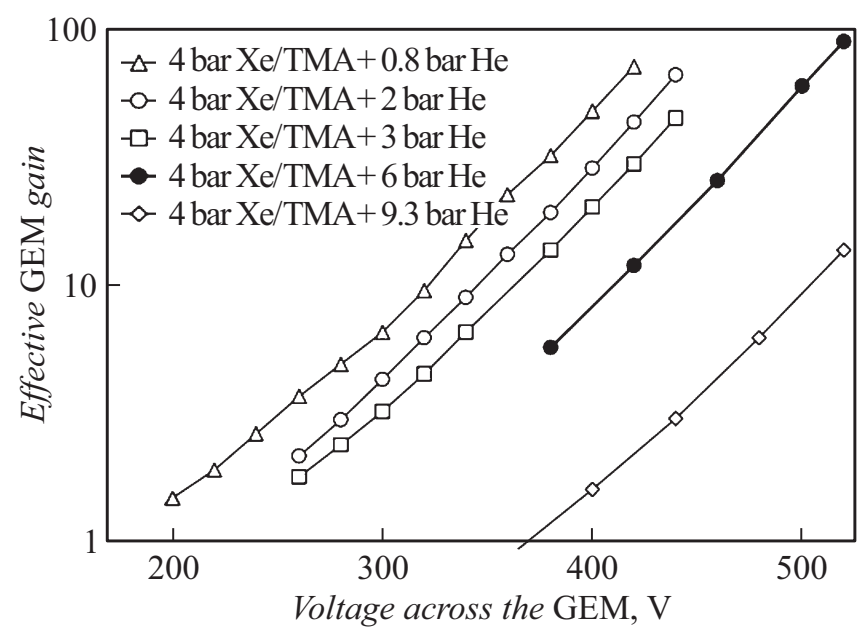

Рис. 30. Эффективное усиление GEM как функция напряжения; результаты получены облучением детектора тепловыми нейтронами на трехкомпонентной смеси Не/Хе/TMА $[42,43]$. 
ции ТХН с учетом флуктуаций импульсов по амплитуде из-за различной ориентации треков относительно детектирующей плоскости достаточным является усиление в интервале 10-100.

В работе [45] сообщается о применении GEM для регистрации треков ТХН в бинарной сцинтиллирующей смеси ${ }^{3} \mathrm{He} / \mathrm{CF}_{4}$ (1/0.4 bar) с записью информации на CCD-камеру. Спектральная чувствительность камеры, максимальная в области 400-1000 nm, хорошо согласуется с длиной волны люминесценции $\mathrm{CF}_{4}$ в отверстиях GEM (250-650 nm). Уникальность GEM в том, что первичные электроны дрейфуют к отверстиям, треки как бы проецируются на микроотверстия, вторичное свечение из которых передается на CCD-камеру imaging.
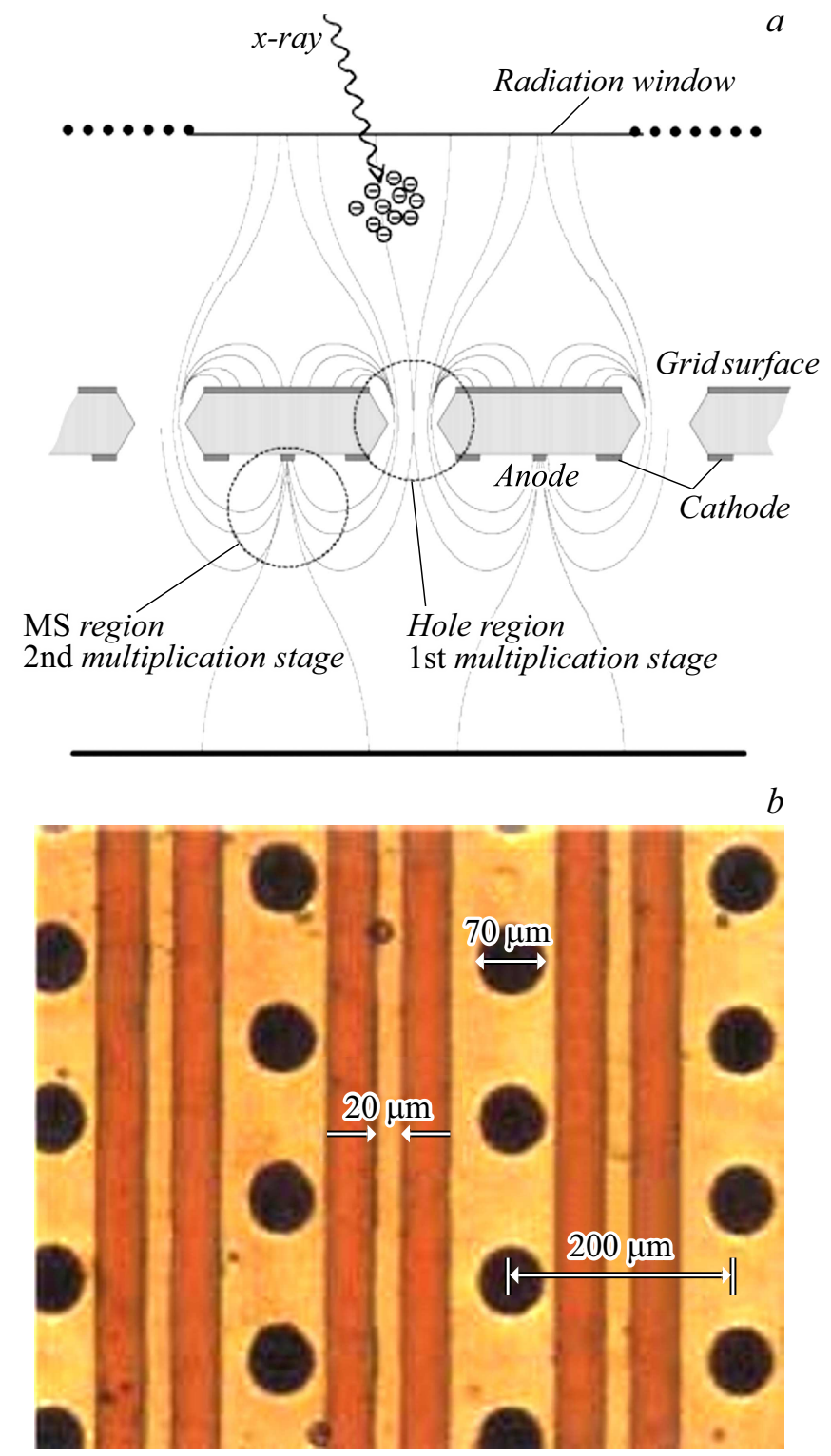

Pис. 31. $a-$ схема детектора на основе MHSP (Micro Hole Strip Plate и линии электрического поля; $b-$ конструкция с видом со стороны стрипов [44].

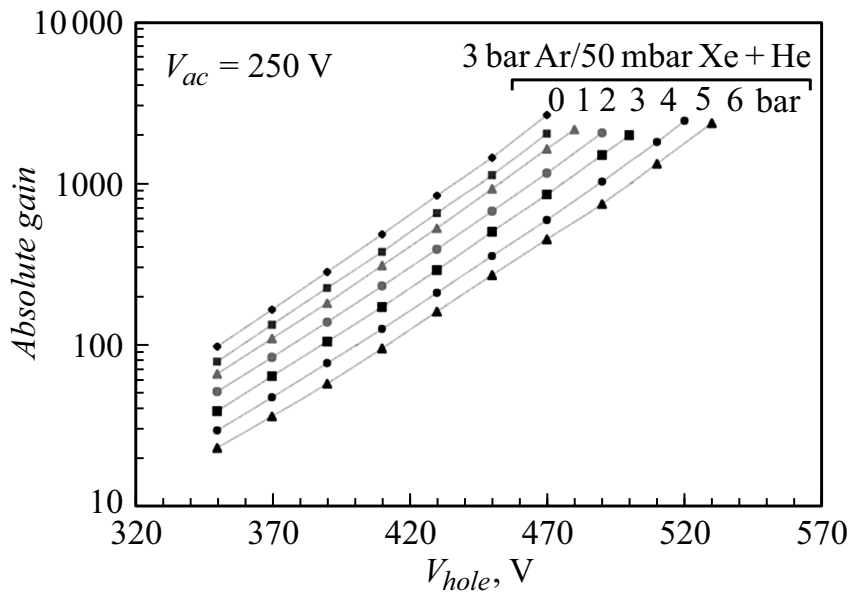

Рис. 32. Эффективное усиление как функция напряжения на MHSP с отверстиями диаметром $70 \mu$ и шагом $200 \mu$, полученное облучением тепловыми нейтронами на трехкомпонентной смеси ${ }^{3} \mathrm{He} / \mathrm{Ar} / \mathrm{Xe}[44]$.

При регистрации момента времени $T_{0}-$ нуля времени по первичному свечению $\mathrm{CF}_{4}$ в смеси ${ }^{3} \mathrm{He} / \mathrm{CF}_{4}$ (с возможной добавкой $\mathrm{TEA}^{22}$ ), сопровождающему развал возбужденного ядра гелия при захвате нейтрона, открывается возможность $3 D$-реконструкции треков протона и тритона при помощи время-проекционной камеры (Time-Projected Chamber, TPC). Проект такой камеры, выполненной на GEM, предложен в работе [32]. Рабочий зазор ТРС-камеры образован между двумя каскадами Double-GEM. Пучок нейтронов направлен параллельно электродам GEM. Первый Double-GEM 1 (верхний на рис. 33) регистрирует сигнал от первичной световой вспышки при помощи фотокатода CSI, нанесенного на первый электрод GEM. B результате определяются две координаты $X_{0}$ и $Y_{0}$ первичной вспышки. Второй Double-GEM $_{2}$ (нижний на рис. 33) регистрирует координаты $X$ и $Y$ от сигналов ионизации, при этом третья координата $Z$ определяется по дрейфу электронов первичной ионизации измерением временно́го интервала, отсчитываемого от $T_{0}$ до появления сигналов на стрипах. Так, определяется недостающая координата $Z_{0}$ первичной вспышки, поскольку точка захвата нейтрона с полученными координатами $X_{0}$ и $Y_{0}$ лежит на проекции треков. Длина треков уже не важна, давление газа может быть атмосферным, что упрощает конструкцию корпуса. Отмечается в качестве примера, что для тепловых нейтронов с $\lambda=1.8 \AA$ с глубиной рабочего зазора $t=5 \mathrm{~cm}$ на смеси ${ }^{3} \mathrm{He} / \mathrm{CF}_{4}$ (2.5/1.5 bar) получена эффективность регистрации $60 \%$, а пространственное разрешение 0.2-0.3 mm (FWHM). Других характеристик в работе [32] не приведено, а новых работ с продолжением не последовало.

В последние годы существенно повышена надежность GEM введением резистивного собирающего электрода

\footnotetext{
22 TЕА - пары триэтиламина.
} 


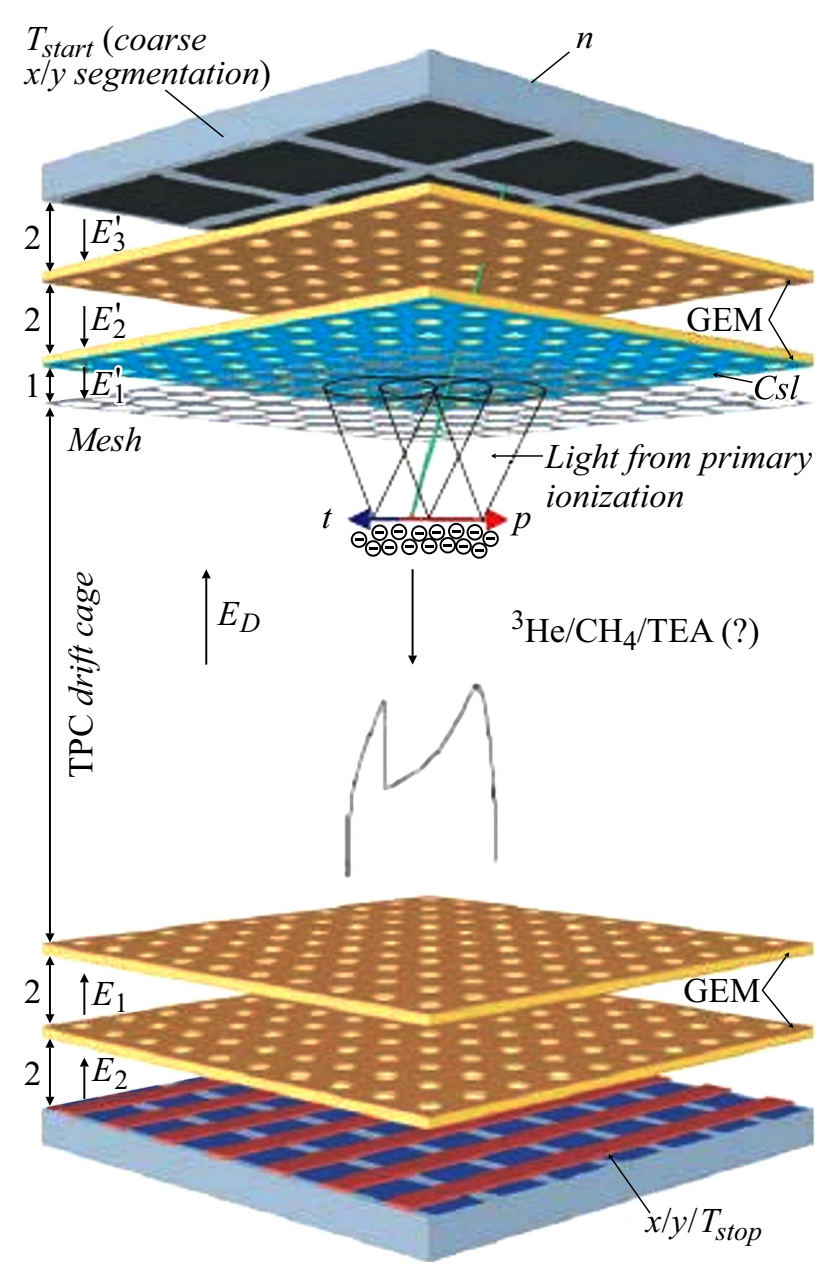

Рис. 33. Проект время-проекционной камеры для $3 D$-реконструкции треков протона и тритона.

из алмазоподобного углерода (Diamond Like Carbon, DLC). Новый умножитель работает без индукционного зазора с отверстиями колодезного типа с быстродействием до $10^{7} \mathrm{~s}^{-1} / \mathrm{cm}^{-2}$ с достаточно большим усилением $10^{4}[46]$.

\section{Заключение}

Изотоп гелия ${ }_{2}^{3} \mathrm{He}$ является наилучшим конвертором для регистрации ТХН. В России этот изотоп пока доступен, поэтому детекторы ТХН для строящегося в ПИЯФ реакторного комплекса ПИК будут выполнены с применением этого конвертора.

Для оптимизации характеристик детекторов ТХН проволочных, микростриповых и микроструктурных широко используются пакеты программ: SRIM, Geant4, Garfield [47].

Рассмотренные варианты проволочных позиционночувствительных детекторов для регистрации ТХН с газовым конвертором ${ }^{3} \mathrm{He}$ отличаются друг от друга быстродействием, пространственным и энергетическим разрешением.

LPSD характеризуются невысоким пространственным разрешением - порядка $1 \mathrm{~cm}$ (что приблизительно составляет $1 \%$ от длины трубки) - и относительно низким быстродействием. Особенностью трубки и ее большим достоинством является то, что она хорошо держит давление, оставаясь относительно тонкостенной. Кроме того, ее характеризует также простота обслуживания сложных дифракционных приборов - ремонтопригодность заменой трубки.

Проволочные камеры MWPC занимают промежуточное положение между LPSD и ионизационными камерами. По сравнению с LPSD у них на порядок лучшее пространственное разрешение поперек проволочек.

Наилучшим детектором ТХН для нейтронных дифрактометров представляется вариант на основе многоканальной ионизационной камеры без сетки Фриша с пэдовым съемом информации. Это техническое решение характеризуют наилучшие энергетическое разрешение и подавление гамма-фона, высокая стабильностью счета. Недостаток - много каналов электроники.

Успешно применяются в дифракционных приборах микростриповые детекторы MSGC. Микростриповые детекторы превосходят MWPC по быстродействию в 100 раз, а по пространственному разрешению в 10 раз. В проектах с регистрацией первичной люминесценции, которая сопровождает захват нейтрона ядром гелия, открываются новые возможности.

Перспективными детекторами являются микроструктурные детекторы GEM, способные заменить MSGC, так как превосходят их по надежности и быстродействию. Регистрация координат первичной световой вспышки приводит к новым возможностям, в частности, к $3 D$-реконструкции треков при пониженном давлении с соответствующим упрощением корпуса.

Микроструктурный детектор ММ, столь же популярный в физике высоких энергий, как и GEM, практически не встречается для регистрации ТХН с гелиевым конвертором. Преимуществом MM над MSGC и GEM является то, что здесь нет диэлектрика на пути движения зарядов, и, как следствие, он должен отличаться высокой стабильностью счета.

Следует подчеркнуть, что для экспериментальной физики созданы и широко применяются 32- и 64-канальные радиационно-стойкие ASIC-чипы с предусилителем, усилителем-формирователем, восстановителем базовой линии, дискриминатором, ADC- и TDC-преобразователями в каждом канале ${ }^{23}$. Их стоимость в многоканальном детекторе, содержащем тысячи каналов, не превышает $10-20 \%$ от стоимости подорожавшего конвертора на изотопе гелия ${ }_{2}^{3} \mathrm{He}$.

\begin{tabular}{lllll}
\hline${ }^{23}$ Iakovidis & G. on behalf of the ATLAS & Muon \\
Collaboration VMM-An ASIC for & Micro-pattern Detector. \\
https://doi.org/10.1051/epjconf/201817407001
\end{tabular}




\section{Финансирование работы}

Работа выполнена при финансовой поддержке Минобрнауки России, Соглашение № 075-02-2018-260 от 26 ноября 2018 г., уникальный идентификационный номер проекта RFMEFI60718X0200. Шифр заявки 2018-14-000-0001-024.

\section{Конфликт интересов}

Авторы заявляют, что у них нет конфликта интересов.

\section{Список литературы}

[1] Eжсов В.Ф., Федоров В.В. // Буклет ПИЯФ. Гатчина. 2007. 41 c. http:nrd.pnpi.spb.ru/pdf/booklet_2007_05_28.pdf

[2] Электронный ресурс. Режим доступа: http:www.pnpi.spb.ru/ustanovki/reaktor-pik

[3] Convert P., Forsyth J.B. (editors). Position-Sensitive Detection of Thermal Neutrons // London: Academic Press, 1983. 429 p. https://inis.iaea.org/search/search.aspx?num=10\&orig_q=source\%3a $\% 22$ ISBN $+0-12-186180-5 \% 22 \&$ lang $=$ en-US\&login $=$ false \&user $=$ External\&src $=$ ics\&sort $=$ date:D:L:d1\&start $=0$

[4] Oed A. // Nucl. Instr. Meth. 1988. A 263. P. 351-359.

[5] Radeka $V$. DOE BES Neutron\&Photon Detector Workshop, Aug. 1-3, 2012. https://portal.slac.stanford.edu/sites/conf_public/nxd2012/presentations/VR_Neutron\%20gas\%20dets_Aug1_2012.pdf

[6] Wilpert Th. // CREMLIN Workshop. St. Petersburg. 2018. May 13-16. https:indico.frm2.tum.de/event/65/sessions/294/attachments/ 202/331/2018_05_14_CREMLIN_Th_Wilpert.pdf

[7] Position Sensitive He3 Neutron Detectors https:www.lndinc.com/product-category/neutron-detectors/ he3-detectors/position-sensitive- he3-neutron-detectors/

[8] Yelon W.B., Tompson C.W., Mildner F.R., Berliner R. // Nucl. Instr. and Meth. 1984. A 226. P. 421-423.

[9] Makino S., Sumita A., Onodera T., Tanaka Y., Hikida N., Ishizawa K. // IEEE Nucl. Sci. Sympos. Conf. Record. 2008.

[10] Glazkov V.P., Naumov I.V., Somenkov V.A., Shil'shtein S.Sh. // Nucl. Instr. Meth. 1988. A 264. P. 367-374.

[11] Radeka V. // Ann. Rev. Nucl. Part. Sci. 1988. Vol. 38. P. 217-277.

[12] Blum W., Riegler $W$., Rolandi L. Particle Detection with Drift Chambers. Berlin, Heidelberg: Springer-Verlag, 2008. 448 p.

[13] Cuello G. J., Darpentigny J., Hennet L., Cormier L.,Dupon J., Homatter B., Beuneu B. // J. Phys. Conf. Ser. 2016. P. 746.

[14] Radeka V., Schaknowski N.A., Smith G.C., Yu B. // Nucl. Instr. Meth. 1998. A419. P. 642-647.

[15] Harder J., Radeka V., Smith G., Yu B. // Nucl. Instr. Meth. 2007. A576. P. 397-402.

[16] Fried J., Harder J.A., Mahler G.J., Makowiecki D.S., Mead J.A., Radeka V., Schaknowski N.A., Smith G.C., Yu B. // Nucl. Instr. Meth. 2002. A478. P. 415-419.

[17] Schoenborn B.P., Schefer J., Schneider D.K. // Nucl. Instr. Meth. 1986. A252. P. 180-187.

[18] Toh K., Nakamura T., Sakasai K., Soyama K., Yamagishi H. // J. Physics: Conf. Ser. 2014. Vol. 528. P. 012045. DOI:10.1088/1742-6596/528/1/012045
[19] Allemand R., Bourdel J., Roudaut E., Convert P., Ibel K., Jacobe J., Cotton P., Farnoux B. Nucl. Instr. Meth. 1975. A126. P. 29-42.

[20] Buffet J.C., Clergeau J.F., Cooper R.G., Darpentigny J., De Laulany A., Fermon C., Fetal S., Fraga F., Guerard B., Kampmann R., Kastenmueller A., Mc Intyre G.J., Manzin G., Meilleu F., Millier F., Rhodes N., Rosta L., Schooneveld E., Smith G.C., Takahashi H., VanEsch P., Van Vuure T.L., Zeitelhack K. // Nucl. Instr. Meth. 2005. A554. P. 392-405.

[21] Kulikov S.A. // CREMLIN Workshop. St. Petersburg. 2018. May 13-16.

https://indico.frm2.tum.de/event/65/sessions/294/attachments/ 202/332/Detectors_FLNP_2018_1-kulikov.pdf

[22] Абдушукуров Д.А. // Известия АН Таджикистана. 2008. № 3 (132).

[23] DENEX-300TN // User Manual and Technical Specification. Lueneburg. February 2008. www.denex-gmbh.de/downloads/manual_300TN.pdf

[24] Andreev V., Ganzha G., Ilyin D., Ivanov E., Kovalenko S., Krivshich A., Nadtochy A., Runov V. // Nucl. Instr. Meth. 2007. A581. P. 123-127.

[25] Yu B., Mahler G.J., Schaknowski N.A., Smith G.C. // IEEE Trans. on Nucl. Sci. 2001. NS 48. N 3. P. 336-340. DOI:0.1109/23.940076

[26] Yu B., Schaknowski N.A., Smith G.C., De Geronimo G., Vernon E.O., Clonts L.G., Britton C L., Frank S.S. // IEEE Nucl. Sci. Symp. Conf. Record. 2008. P. 1878-1881. DOI: $10.1109 /$ NSSMIC.2008.4774757 https:ieeexplore.ieee.org/document/4774757

[27] Schaknowski N.A., Smith G.C., Yu B., Doumas J. // IEEE Nucl. Sci. Sympos. Conf. Record. 2005.

[28] Oed A. // Nucl. Instr. Meth. 2004. A 525. P. 62-68.

[29] Clergeau J.F., Convert P., Feltin D., Fischer H.E., Guérard B., Hansen T., Manzin G., Oed A., Palleau P. // IEEE Trans. 2001. NS Vol. 48. N 4. P. 1075.

[30] Guérard B. // Proc. Workshop Neutron Detectors for Spallation Sources. 1998.

[31] Guérard B. // Neutron News. 2005. Vol. 16. N 4. P. 16-21. DOI:10.1080/10448630500454445.

[32] Gebauer B. // Nucl. Instr. Meth. 2004. A 535. P. 65-78.

[33] Convert P., Hansen T., Oed A., Torregrossa J. // Physica B. 1997. Vol. 241-243. P. 195-197.

[34] Hansen T., Henry P.F., Fischer H.E., Torregrossa J., Convert P. // Meas. Sci. Technol. 2008. Vol. 19. P. 034001 (6p). DOI:10.1088/0957-0233/19/3/034001

[35] Tanimori T., Nishi Y, Ochi A., Nishi Y. // SPIE's International Symposium on Optical Science, Engineering and Instrumentation. 1999; arXiv:hep-ex/9905006. DOI:10.1016/S0168-9002(99)00619-1.

[36] Tanaka H., Nakamura T., Yamagishi H., Soyama K., Aizawa K., Ochi A., Tanimori T. // IEEE Transaction on NS. 2006. Vol. 53. N 4. P. 2264.

[37] Fujita K., Takahashi H., Siritiprussamee P., Niko H., Ino T., Shimizu H.M., Kishimoto S., Furusaka M., Toyokawa H., Kanazawa M. // IEEE Nucl. Sci. Sympos. Conf. Record. 2006.

[38] Manzin G., Guerard B., Fraga F.A.F., Margato L.M.S . / Nucl. Instr. Meth. 2004. A 535. P. 102-107.

[39] Morozov A., Margato L.M.S., Fraga M.M.F.R., Pereira L., Fraga F.A.F. // JNST. 2012. Vol. 7. P. 02008.

[40] Sauli F. // Nucl. Instr. Meth. 1997. A386. P. 531-534.

[41] Giomataris Y., Rebourgeard Ph., Robert J.P., Charpak G. // Nucl. Instr. Meth. 1996. A376. P. 29-35. 
[42] Vuure T.L., Eijk C.W.E., Frag F., Hollander R.W., Margato L. // IEEE Trans. on Nucl. Sci. NS. 2001. Vol. 48. N 4. P. $1092-1094$.

[43] Vuure T.L. // Theses PhD, Delft University Press. Netherlands. 2004.

[44] Veloso J.F.C.A., Amaro F., Santos J.M.F., Mir J.A., Derbyshire G.E., Stephenson R., Rhodes N.J., Schooneveld E.M. // IEEE Trans. Nucl. Sci. NS 2004. Vol. 51. N 5. P. 2104-2109.

[45] Fraga F.A.F., Margato L.M.S., Fetal S.T.G., Fraga M.M.F.R., cMarques R.F., Policarpo A.J.P.L., Guerard B., Oed A., Manzini G., Vuure T.L. // Nucl. Instr. Meth. 2002. A478. P. 357-361.

[46] Bencivenni G., Oliveira R., Felici G., Gatta M., Giovannetti M., Morello G., Ochi A., Poli Lener M., Tskhadadze E. // JINST. 2019. Vol. 14. P. 05014.

[47] Vander Ende B.M., Rand E.T., Erlandson A., Li L. // Nucl. Instr. Meth. 2018. A894. P.138-144. 